\title{
Nanoparticles for cancer therapy: current progress and challenges
}

\author{
Shreelaxmi Gavas ${ }^{1}$, Sameer Quazi², Tomasz M. Karpiński ${ }^{3 *}$
}

1. Clinical Analyst, Department of Life Sciences, GenLab Biosolutions Private Limited, Bangalore, Karnataka, India. (560043)

Email: Colonel.quazi@gmail.com

2. Founder \& CEO, GenLab Biosolutions Private Limited, Bangalore, Karnataka, India. (560043)

Email: Shreelaxmi012@gmail.com

3. Chair and Department of Medical Microbiology, Poznan University of Medical

Sciences, Wieniawskiego 3, 61-712 Poznan, Poland.

Email: tkarpin@ump.edu.pl

\begin{abstract}
:
Cancer is one of the leading causes of death and morbidity with a complex pathophysiology. Traditional cancer therapies include chemotherapy, radiation therapy, targeted therapy, and immunotherapy. However, limitations such as lack of specificity, cytotoxicity, and multi-drug resistance pose a substantial challenge for favorable cancer treatment. The advent of nanotechnology has revolutionized the arena of cancer diagnosis and treatment. Nanoparticles $(1-100 \mathrm{~nm})$ can be used in the treatment of cancer owing to their specific advantages such as biocompatibility, reduced toxicity, more excellent stability, enhanced permeability and retention effect, and precise targeting. Nanoparticles are classified into several main categories. The nanoparticle drug delivery system is particular and utilizes tumor and tumor environment characteristics. Nanoparticles not only solve the limitations of conventional cancer treatment but also overcome multidrug resistance. Additionally, as new multidrug resistance mechanisms are unraveled and studied, nanoparticles are being investigated more vigorously. Various therapeutic implications of nano-formulations have created brand new perspectives for cancer treatment. However, a majority of the research is limited to in vivo and in vitro studies, and the number of nano-drugs that are approved has not much amplified over the years. In this review, we discuss numerous types of nanoparticles, targeting mechanisms along with approved nanotherapeutics for oncological implications in cancer treatment. Further, we also summarize the current perspective, advantages, and challenges in clinical translation.
\end{abstract}

Keywords: Cancer, nanoparticles, chemotherapy, cellular targeting, multidrug resistance, cryosurgery, scale-up. 


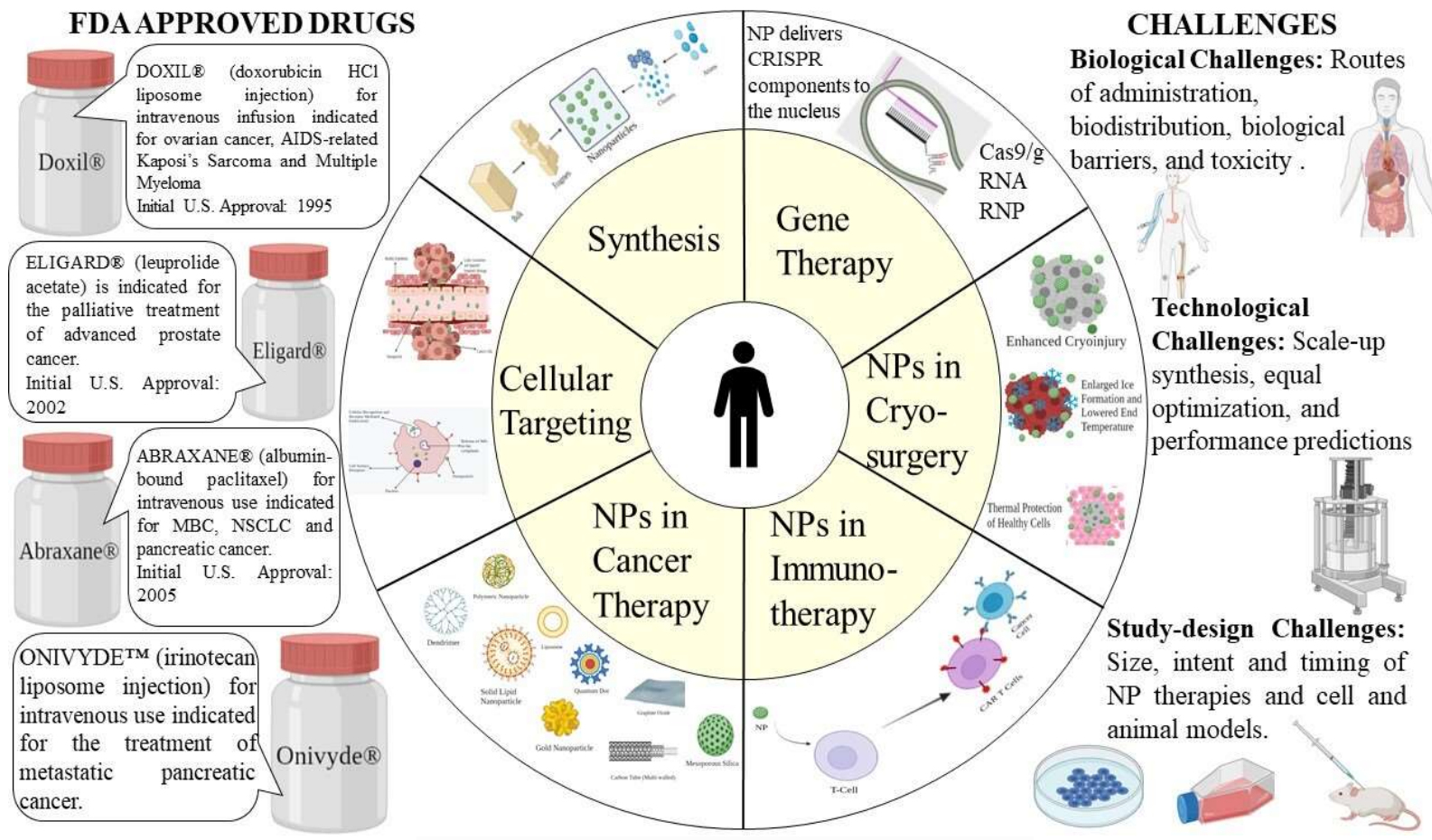

Figure 1: Nanoparticles for cancer therapy

(Graphical Abstract) 


\section{Introduction:}

Cancer is a generic term for a set of diseases characterized by uncontrolled, random cell division and invasiveness. Extensive efforts over several years have been focused on detecting various risk factors for cancer. For some cancers, aetiology has been influentially associated to specific environmental (acquired factors) such as radiation and pollution. However, unhealthy lifestyle like poorly balanced diet, tobacco consumption, smoking, stress, and lack of physical activity has a strong impact on cancer risk determination [1]. While these external factors have been recognized as major causes of cancer, the involvement of mutations of proto-oncogenes, tumor suppressor genes expression patterns and the genes involved in DNA repair has been tough to estimate. Only 5-10\% of cancer cases are linked with inherited genetics [2]. Advancing age is another crucial risk factor for cancer and for many individual cancer types.

Cancer is one of the significant public health problems globally and is the second leading cause of death. According to American Cancer Society, the number of new cases is anticipated to be 1.9 million by the end of year 2021 [3]. The conventional therapeutic approaches used in the treatment of cancer include surgery, chemotherapy, radiation therapy, targeted therapy, immunotherapy, and hormone therapy [4,5]. Although chemotherapy and radiation therapy possess cytostasis and cytotoxicity abilities [6], these approaches are often linked with acute side effects and high risk of recurrences. The most common side effects that are induced by include neuropathies, suppression of bone marrow, gastrointestinal and skin disorders, hair loss, and fatigue. Besides, there are a few drug-specific side effects such as anthracyclines and bleomycin-induced cardiotoxicity and pulmonary toxicity [7].

The advent of targeted therapy has made growth in precision therapy. However, there are still many inevitable adverse effects, such as multi-drug resistance which limits therapeutic efficacy [8]. Immunotherapeutic agents have yielded promising results by not only treating primary cancer but by preventing distant metastasis and lowering the rate of recurrence [9]. Nevertheless, autoimmune disease is a major side-effect of immunotherapy. Additionally, studies and shreds of evidence suggest that immunotherapy is known to be less effective against solid tumors than lymphoma [10]. This is because these cancers create an unusual extracellular matrix (ECM) which is quite challenging for immune cells to infiltrate [11]. These newly evolved targeted therapies and immunotherapies interfere with signaling pathways that play a vital role in malignant behaviors and normal homeostatic functions of the epidermis and dermis and cause dermatologic adverse events (dAEs) [12].

Taking all of these details into consideration, the demand for the advancement of novel strategies for seeking precise therapy of cancer has gained momentum in recent years. Recent efforts have been made to address the limitations of existing therapeutic approaches using nanoparticles. Nanoparticle-based drug delivery systems have reflected benefits in cancer treatment and management by demonstrating good pharmacokinetics, precise targeting, reduced side effects, and drug resistance $[13,14]$.

On the heels of the advancements of nanotechnology, a number of nanotherapeutic drugs have been commercialized and is widely marketed, and many more have entered the clinical stage since 2010. Nanotherapeutic drugs have made progress in the domain of drug delivery systems and in anti-tumor multidrug resistance (MDR) by providing a chance for drug combination therapy and inhibition of drug resistance mechanisms [15]. The pioneer effort to apply nanotechnology in medicine at ETH Zurich in the 1960s [16]. This combination has proved to be a better amalgamation in developing various diagnostic devices and better therapies. This review mainly focuses on basic principles of the application of nanotherapeutics, current challenges prospects, and describes the path of future research. 


\section{Nanoparticles}

Nanoparticles (NPs) are technically defined as particles that have one dimension less than $100 \mathrm{~nm}$ with unique properties that are usually not found in bulk samples of the same material [17]. Depending on the nanoparticle's overall shape, these can be classified as 0D, 1D, 2D or $3 \mathrm{D}$ [18]. The basic composition of nanoparticles is quite complex comprising of the surface layer, the shell layer, and the core, which is fundamentally the central portion of the NP and usually termed as the NP itself [19]. Owing to their exceptional features like high surface: volume ratio, dissimilarity, sub-micron size, and enhanced targeting system, these materials have gained a lot importance in multidisciplinary fields.

NPs are found to have deep tissue penetration to increase enhanced permeability and retention (EPR) effect. Besides, the surface characteristics impact bioavailability and half-life by effectively crossing epithelial fenestration [20]. For example, NPs that are coated with polyethylene glycol (PEG), a hydrophilic polymer, decrease opsonization and hence circumvent immune system clearance [21]. Additionally, it is possible to optimize the rate of release of drug or active moiety through manipulating particle polymer characteristics. Altogether, the distinct properties of NPs regulate their therapeutic effect in cancer management and treatment.

\subsection{Synthesis of NPs}

The NPs are of various different shapes, sizes, and structures. To achieve this, numerous synthesis methods are adopted. These methods can be largely categorized into two major groups: 1) Bottom-up approach and 2) Top-Down approach. These approaches can be further classified into different subclasses based on reaction conditions and operation.

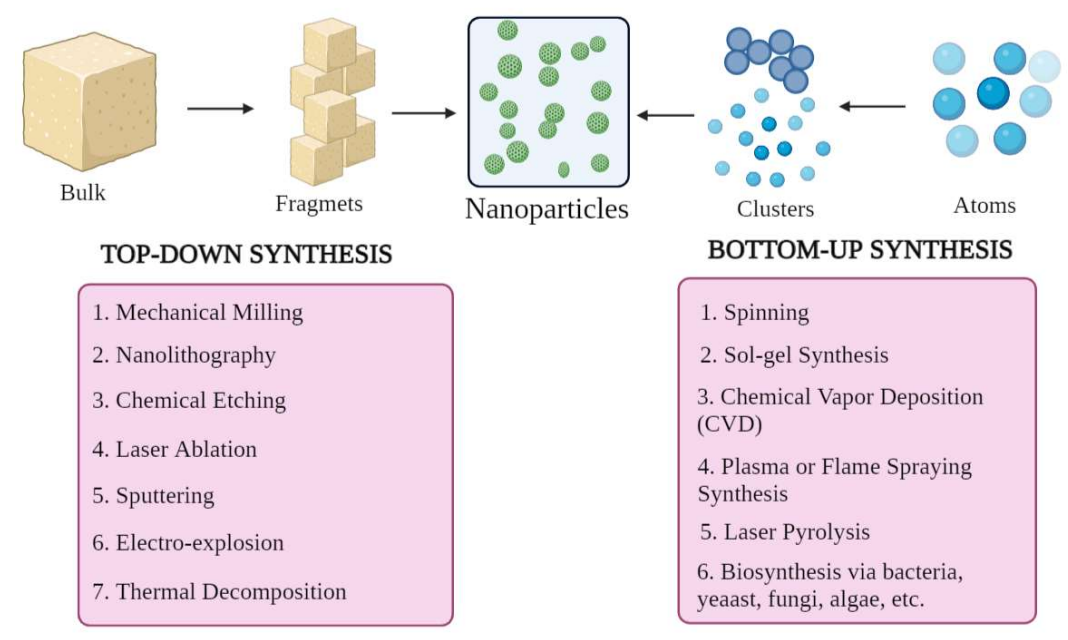

Figure 2. Classification of NP Synthesis (a) top-down and (b) bottom-up approaches.

\subsubsection{Bottom-up approach}

This method involves the building up of material from atom to clusters to NPs, i.e., building from simpler substances and hence known as constructive method [22]. Some commonly used methods are spinning, sol-gel synthesis, chemical vapor deposition (CVD), plasma or flame spraying synthesis, laser pyrolysis, and biosynthesis. 


\subsubsection{Top-down approach}

This is also known as destructive method which involves the reduction of bulk material or substance to synthesize NPs. A larger molecule is broken down or decomposed into smaller units which are in turn converted into NPs [23]. This includes techniques such as mechanical milling, nanolithography, chemical etching, laser ablation, sputtering, electro-explosion, and thermal decomposition.

Remarkably, the morphological parameters such as size, shape and charge of NPs can be modified by changing the reaction conditions and other synthesis parameters [24]. Besides, the growth mechanism also determines the chemical properties of NPs. Hence understanding the growth mechanism is very essential to synthesize required NPs.

\section{Mechanisms of Cellular Targeting}

For effective cancer therapy, it is very essential to develop or engineer drug or gene delivery system that has an excellent ability of specific targeting of tumor cells sparing the normal healthy cells. This enhances therapeutic efficacy, thereby shielding normal cells from the effect of cytotoxicity. This can be achieved by the well-organized delivery of NPs into the tumor microenvironment (TME), indirectly targeting cancer cells. These nano-formulations should pass through numerous physiological and biological barriers. These barriers are complex systems of several layers (epithelium, endothelium, and cellular membranes) and components (mechanical and physicochemical barriers and enzymatic barriers). These facts impose specifications with respect to the size, biocompatibility, and surface chemistry of NPs to prevent unspecific targeting. However, mere cytosolic internalization of an NP drug molecule does not mean it reaches its subcellular target. Specific engineering and optimization are mandatory to enable cellular or nuclear targeting.

Several studies have been carried out so far and several more are in progress to discover NPbased drug targeting design. These nanocarriers typically should possess certain fundamental characteristics such as 1) ability to remain stable in the vascular system (blood) until they reach their target, TME 2) to escape the reticuloendothelial system (RES) clearance, 3) escape mononuclear phagocyte system (MPS), 4) accumulate in TME via tumor vasculature, 5) highpressure penetration into the tumor fluid, and 6) reach the target and only interact with tumor cells [25]. The vital aspects such as surface functionalization, physicochemical properties, and pathophysiological characteristics regulate the process of NP drug targeting.

Generally, NPs that are considered apt for cancer treatment have a diameter range of 10-100 $\mathrm{nm}$. In order to understand the process of interaction and crosstalk between NP carriers and cancer cells and tumor biology, it is important to address the targeting mechanisms. The targeting mechanisms can be broadly classified into two groups, passive targeting, and active targeting.

\subsection{Passive Targeting}

The observation of preferential accumulation of few macromolecules in cancer cells was found in late 1980s. The first macromolecule to be reported to accumulate in the tumor was poly(Styrene-co-Maleic Acid)-NeoCarzinoStatin (SMANCS) by Matsuura and Maeda [26]. On further studies, this preferential distribution was attributed to the occurrence of fenestrations that are found in the damaged tumor blood vessels and to the poor lymphatic drainage, the amalgamation of which is known as "enhanced permeation and retention effect".

Under certain conditions such as hypoxia or inflammation, the endothelium layer of the blood vessels become more permeable [27]. Under hypoxia situations, the tumor cells which are 
rapidly growing tend to put in action more blood vessels or engulf the existing ones to cope up. This process is known as neovascularization. These new blood vessels are leaky as these have large pores that lead to poor perm-selectivity of tumor blood vessels as compared to the normal blood vessels [28, 29]. These large pores or fenestrations range from 200 to $2000 \mathrm{~nm}$ depending on the cancer type, TME and its localization [30]. This rapid and defective angiogenesis provides very little resistance to extravasation and permits NPs to diffuse from such blood vessel and ultimately collect within cancer cells.

In normal tissues, the drainage of ECF (extracellular fluid) into lymphatic vessels happens frequently at an average flow velocity of $0.1-2 \mu \mathrm{m} / \mathrm{s}$ which maintains constant drainage and renewal [31]. When a tumor is formed, the lymphatic function gets derailed which results in minimal interstitial fluid uptake [32]. This feature contributes to the NPs retention as they are not get cleared and hoard in the tumor interstitium. This process denotes the enhanced retention part of the EPR effect. This exceptional feature does not apply to molecules that have short circulation time and gets washed out rapidly from the cancer cells. Hence, to improve such situations, encapsulation of these small molecules in nan-sized drug carriers is routinely carried out to enhance their pharmacokinetics, provide tumor selectivity and reduce side effects [33].

Over and above the EPR effect, and TME is a vital feature in passive targeting. One of the important metabolic features of rapidly proliferating tumor cells is glycolysis. This is the chief source of energy for cell division [34] and makes the surrounding environment acidic. This lowered $\mathrm{pH}$ of TME can be exploited to use $\mathrm{pH}$ sensitive NPs that release drugs at low $\mathrm{pH}$ [35].

This type of tumor targeting is termed as 'passive'. Passive targeting mainly banks on the different tumor biology (vascularity, leakiness) and carrier characteristics (size and circulation time). This type of tumor targeting does not possess a ligand that is specific for a certain type of tumor cells. The EPR effect greatly relies on the fundamental tumor biology such as 1) the degree or extent of angiogenesis and lymphagiogenesis 2) the extent or degree of perivascular tumor invasion, and 3) intratumor pressure. These factors, combined with physicochemical characteristics of NPs determines the efficiency of NP drug delivery system.

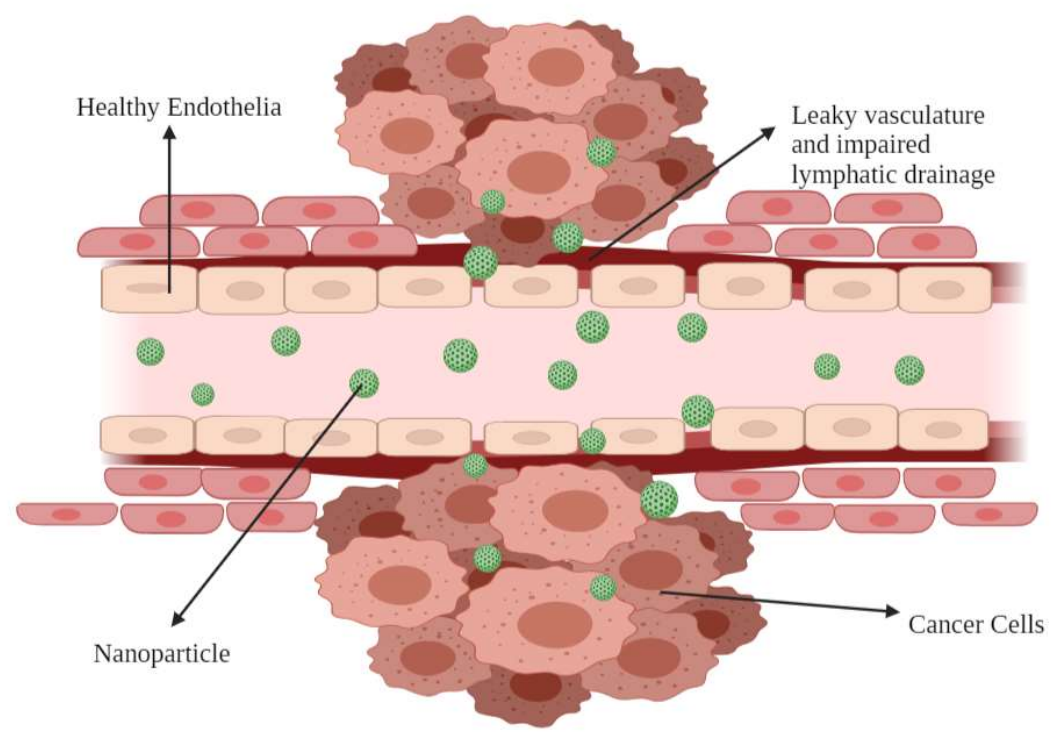

Figure 3. Pictorial representation of passive cellular targeting. 


\subsubsection{Examples of Passive Targeting:}

Taxanes is one of the most successful drug group that is used in cancer treatment. Paclitaxel has shown great potency against a broad range of cancers. Breast cancer, lung cancer (small cell and non-small cell) and ovarian cancer are the most treated histologies with taxanes. USFDA, in 2005, approved Abraxane ${ }^{\circledR}$ (albumin-bound paclitaxel, Abraxis Bio-Sciences) which is used for advanced or metastatic breast cancer (MBC).

Abraxane ${ }^{\circledR}$ is an anti-microtubule drug that stabilizes the microtubules by preventing depolymerization. This occurs when the drug encourages the microtubule assembly from tubulin dimers. This gained stability hinders microtubules reorganization which is very important during interphase and mitotic cellular functions. Paclitaxel, a well-used taxane, during cell cycle and mitosis, triggers unusual microtubules array along with multiple asters respectively. Abraxane ${ }^{\circledR}$ alone or in combination with another cytotoxic agent such as gemcitabine diminish pancreatic stroma in pancreatic cancer xenograft mouse models [36].

Genexol $\mathrm{PM} \AA$ is an innovative nano-formulation of paclitaxel and sterile lyophilized polymeric micellar formulation without CrEL. Genexol PM®, according to trials, was found to have a three-times higher maximum tolerated dose (MTD) in nude mice. Besides, the biodistribution exhibited two- to three-times higher levels in different tissues such as liver, spleen, kidney and lung and more prominently in cancer cells. This has been approved in South Korea to treat MBC. It is still under phase II clinical study in the US in attempt to treat pancreatic cancer [37].

DaunoXome ${ }^{\circledR}$ (liposomal daunorubicin; Gilead Science/Diatos) is an anti-cancer medicine which reduces tumor cell growth. The active substance is daunorubicin. This is a special formulation of daunorubicin (in liposome form) which is used to treat Kaposi's sarcoma which is a form of cancer that affects the skin, but which also affects the lungs and intestines. This was approved by US-FDA in 1996 [38].

Although, neovascularization and angiogenesis influences NP diffusion, it leads to greater interstitial pressure which in contrast, inhibits the accumulation of NPs. Moreover, due to heterogenous blood supply, the growth of the tumor cells is irregular, i.e., the cells that are close to blood vessels divide faster than those that are away from the blood vessel or deep in the core forming hypoxic or necrotic area within the tumor. This irregular leaking, causes high interstitial pressure impedes drug delivery and accumulation besides slows down the process of neovascularization [33]. However, it is possible to control EPR effect, either mechanically or chemically. These include nitric oxide, peroxynitrate, bradykinin, VPF (vascular permeability factor), ultrasound, radiation, hyperthermia, etc. However, there are certain limitations and contra-indications.

\subsection{Active Targeting}

Active targeting depends on the use of specific ligands or molecules, like transferrin and folate which binds to molecules or receptors which are specifically expressed or over-expressed on the target cells (diseased organs, tissues, cells or subcellular domains) [39]. This type of targeting is called as ligand-mediated targeting [40]. Here, the NPs that possess ligand with specific functions such as retention and uptake need to be in the proximity of the target so that there is greater affinity. This strategy enhances the changes of NPs binding to the cancer cell which in turn enhances the drug penetration. The foremost indication of the same was observed in 1980 with antibodies grafted in the surface of liposomes [33], followed by other various types of ligands like peptides, aptamers. Hence, the main method is intended at increasing the crosstalk between NPs and the target without fluctuating the total biodistribution [41]. The vital 
mechanism of active targeting or ligand-mediated targeting is the ligand identification by the target substrate receptors. The illustrative ligands may be anything ranging from proteins, peptides, antibodies, nucleic acids, sugars to small molecules like vitamins etc. [42]. The most commonly studied receptors are transferrin receptor, folate receptor, glycoproteins and the epidermal growth factor receptor (EGFR). Ligand-target interaction triggers infolding of the membrane and internalization of NPs via receptors-mediated endocytosis. There are various mechanisms by which active targeting takes place. The majority of tumor targeting is done by the tumor cell targeting in general by NPs. This process improves their cell penetration. As stated before, transferrin is one of the widely studied receptor.It is a type of serum glycoprotein that aids in transporting iron into cells. These receptors are found to be overexpressed in most of the tumor cells, especially solid tumors and are expressed at lower levels in healthy cells. Hence, we can modify the NPs with associated ligands that specifically target transferrin [43]. For instance, A2780 ovarian carcinoma cells overexpress transferrin. This feature is used by transferrin-modified PEG- phosphatidyl-ethanolamine (Tf-Mpeg-pe) NPs that specifically targets such cells [44]. Another alternative method is to aim targeting cells that are adjacent to cancer cells such as angiogenic endothelial cells. These cells also have a close contact with tumor blood vessels. With this strategy, it is possible to create hypoxia and necrosis by reducing the blood supply to the cancer cells. It has been found out that tumor tissues are more acidic than normal ones. This has been extensively explained by Warburg effect [45]. This explains the shift of cancer cell metabolism into glycolysis forming lactic acid. When the lactic acid accumulates, the cell dies. To cope up to this situation, the cells start overexpressing proton pumps that pumps out excess lactic acid into the extracellular environment making it more acidic. Therefore, liposome-based $\mathrm{pH}$ sensitive drug delivery system has been studied.

The crosstalk of ligand coated NPs with target cancer cells are improved by the multivalent nature of the NPs. The design of such NPs is in fact complex as NP architecture and ligandtarget chemistry influence the efficacy of the entire method. Other factors such as route of administration, physicochemical properties such as ligand density [46], and size of NPs [47] contribute to the system's success.

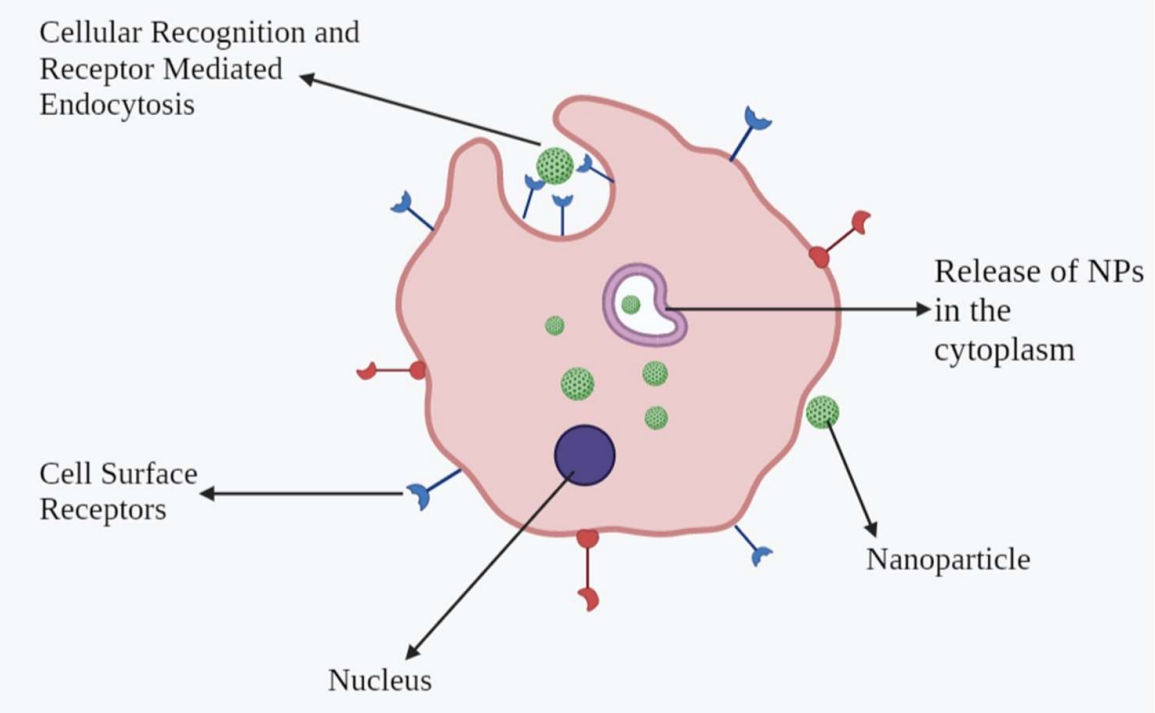

Figure 4. Pictorial representation of active cellular targeting. 


\subsubsection{Examples of Active Targeting:}

EGFR, a member of the ErbB family of tyrosine kinase (TK) receptors, is overexpressed in various types of cancer, especially with squamous cell histology. Gold NPs with anti-EGFRPEG-AuNPs and anti-IgG-PEG-AuNPscan be used to target the human SCC [48].

Herceptin ${ }^{\circledR}$ is a therapeutic drug that targets human EGF receptor-2 (HER2) that is overexpressed on breast cancer cell surfaces. HER2-targeted PEGylated liposomal doxorubicin was developed to reduce cardiotoxicity, a known side effect of anthracyclines [49].

The surface of the tumor endothelium expresses a glycoprotein known as vascular cell adhesion molecule-1 (VCAM-1) that is involved in the process of angiogenesis. A study has highlighted NPs that target VCAM-1 in the breast cancer model, indicating its potential role [50].

Folic acid, also known as vitamin B9, is vital in nucleotide synthesis. Folic acid is internalized by the folate receptor that is expressed on the cells. However, tumor cells overexpress FR- $\alpha$ (alpha isoform of folate receptor) while FR- $\beta$ is overexpressed in liquid cancer cells [51]. Targeting the folate receptors by NPs has been currently for specific cancer treatments [52, 53].

\section{Nanoparticles in Cancer Therapy}

NPs used extensively in drug delivery systems include organic NPs, inorganic NPs, and hybrid NPs.

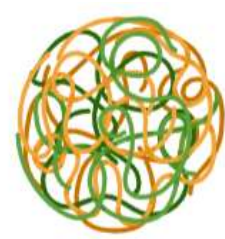

Polymeric Nanoparticle

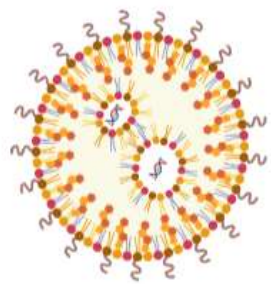

Solid Lipid

Nanoparticle

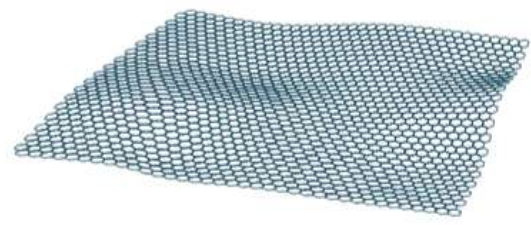

Graphite Oxide

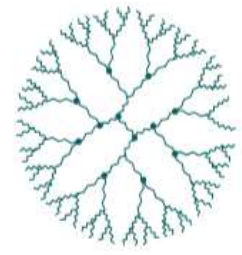

Dendrimer

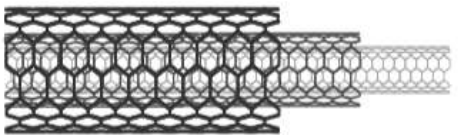

Carbon Tube (Multi walled)

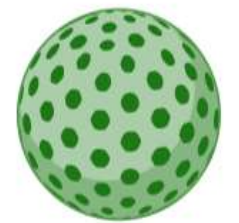

Mesoporous Silica Nanoparticle

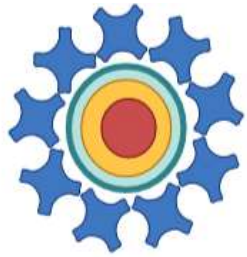

Quantum Dot

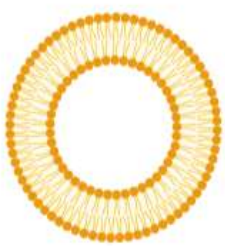

Liposome

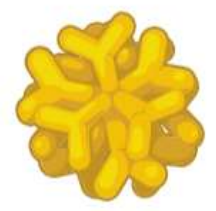

Gold Nanoparticle

Figure 5. Various types of nanomaterials used in cancer therapy 


\subsection{Polymeric Nanoparticles}

Polymeric nanoparticles (PNPs) are well-defined as "colloidal macromolecules" with size ranging from $10-1000 \mathrm{~nm}$ with specific structural architecture formed by different monomers [54]. The drug is either entrapped or attached to NPs'exterior, creating a nanosphere or a nanocapsule to achieve regulated drug release in the target [55]. Initially, PNPs were made up of nonbiodegradable polymers such as polyacrylamide, polymethylmethacrylate (PMMA), and polystyrene [56]. However, the accumulation of these led to toxicity due to difficulty in eliminating these from the system. Biodegradable polymers such as polylactic acid, poly(amino acids), chitosan, alginate, albumin are now being used and are known to reduce toxicity, enhance drug release, and biocompatibility [57]. Proven research has reflected on the fact that by coating PNPs with polysorbates and by using polysorbates surfactant effect. Exterior coating enhances NPs' interactions with the endothelial cell membrane of blood-brain barrier (BBB) [58].

A study showed that nano-capsules loaded with indomethacin involved a substantial decrease in the size of the tumor and improved survival in a xenograft glioma model in rats [59]. This is a growing field with more than ten polymeric NPs containing anticancer drugs are under clinical development. A few examples include paclitaxel poliglumex (Xyotax), PEGcamptothecin (Prothecan), Modified dextran-camptothecin (DE 310), HPMA copolymerDACH-platinate (AP5346), HPMA copolymer-platinate (AP 5280), HPMA copolymerpaclitaxel (PNU166945), and HPMA copolymer-doxorubicin galactosamine (PK2) [60].

\subsection{Dendrimers}

Dendrimers are spherical polymeric macromolecules with defined hyperbranched architecture. Highly branched structures are the characteristic feature of dendrimers. Typically, the synthesis of dendrimers is initiated by reacting an ammonia core with acrylic acid. This reaction results in forming a "tri-acid"molecule, that further reacts with ethylenediamine to yield "tri-amine", a GO product. This product further reacts with acrylic acid to give rise to hexa-acid, which further produces "hexa-amine" (Generation 1) product and so on [61]. Typically, the size of the dendrimers ranges from 1-10 nm. However, the size may reach up to $15 \mathrm{~nm}$ [62]. Given their specific structure like defined molecular weight, adjustable branches, bioavailability, and charge, these are used to target nucleic acids. Some dendrimers that are widely used are polyamidoamine (PAMAM), PEG (poly(ethyleneglycol)), PPI (polypropylenimine), and TEA (triethanolamine) [63].

A PAMAM dendrimer was initially designed to achieve MDR management. DNA assembled PAMAM dendrimers have been described extensively. As compared with animals treated with the single-agent chemotherapy, the synthesized dendrimers significantly delayed the growth of epithelial cancer xenografts [64].

\section{3 mAb Nanoparticles}

Monoclonal antibodies are widely used in cancer treatment for their particular targeting abilities [65]. These mAb are now combined with NPs to form antibody-drug conjugates (ADCs). These are proved to be highly specific and compelling than cytotoxic drugs or $\mathrm{mAb}$ alone. For instance, an antibody-drug NP consisting of paclitaxel core and a surface modified with trastuzumab presented a better anti-tumor efficacy and lower toxicity than single-agent paclitaxel or trastuzumab alone in HER2 positive breast epithelial cell control [66]. 


\subsection{Extracellular vesicles}

Extracellular vesicles (EVs) are double layered phosphor-lipid vesicles ranging from 50$1000 \mathrm{~nm} n$ size [67]. EVs are continuously secreted by different cells types and vary in origin, size, and composition. EVs are divided into three classes - 1) exosomes, 2) microvesivcles and 3) apoptotic bodies [68]. NPs combined with exosomes are widely used as they have lipid and molecules that are very similar to origin cells. Besides, they escape the immune surveillance and internalize very quickly within the cancer cells. They act as natural vehicles by delivering cytotoxic drugs and other anti-tumor drugs to the target sites. Exosomes loaded with doxorubicin (exoDOX) is the best example. exoDOX is used to treat breast cancer and has showed great results as compared to conservative treatment with doxorubicin by enhancing the cytotoxicity and avoiding cardiotoxicity [69]. Exosome NPs have intrinsic biocompatibility feature, advanced chemical stability, and intracellular communications as compared to synthetic NPs. Nevertheless, drawbacks like deficiency of standard conditions for exosomal isolation and purification are very crucial and needs to be addressed [70,71].

\subsection{Liposomes}

These are spherical vesicles comprising of phospholipids which may be either uni-lamellar or multi-lamellar to encapsulate drug molecules [72]. Liposomes are unique in having characteristics such as low intrinsic toxicity, week immunogenicity, and biological inertness [73]. Liposomes are the first nano-scale drug that was approved in 1965 [74]. A typical liposome structure is composed of a "hydrophilic core" and a "hydrophobic phospholipid bilayer". This unique architecture makes it possible for them to entrap both hydrophilic and hydrophobic drugs, that they effectively protect the entrapped drug from environmental degradation in circulation [75].

Liposomes provide an excellent platform for drug delivery such as doxorubicin, paclitaxel, and nucleic acid as well by demonstrating higher anti-tumor efficacy and enhanced bioavailability [76]. Doxil® and Myocet ${ }^{\circledR}$ are approved liposome-based formulations of daunorubicin used to treat MBC [77,78]. However, due to shortcomings like decreased encapsulation efficacy, speedy removal by MP, cell adsorption, and short shelf life, the application of liposome-based NPs is limited.

\subsection{Solid Lipid nanoparticles (SLN)}

They are colloidal nanocarriers (1-100 nm) made up of a phospholipid monolayer, emulsifier, and water [79]. These are known as zero-dimensional nanomaterials. The lipid component may be triglycerides, fatty acids, waxes, steroids, and PEGylated lipids [80]. Unlike conventional liposomes, SLNs have a "micelle-like structure" within which the drug is entrapped in a nonaqueous core. Examples include mitoxantrone-loaded SLN, which has showed reduced toxicity and enhanced bioavailability [81]. The incorporation of doxorubicin and idarubicin by SLN in "P388/ADR leukemia cells" and the "murine leukemia mouse model" has shown positive results [82].

\subsection{Nanoemulsions}

Nano-emulsions are colloidal NPs with heterogeneous mixtures of oil droplet in aqueous media ranging from $10-1000 \mathrm{~nm}$ [83]. Three representative types of nano-emulsions that can be made are 1) oil-in-water system 2) water-in-oil system and 3) bi-continuous nano-emulsions. Membrane-modified nano-emulsions have been extensively studied. For instance, nanoemulsions loaded with spirulina and paclitaxel showed an improved anti-tumor effect by regulating immunity through TLR4/NF- $\mathrm{kB}$ signaling pathways [84]. Nano-emulsion 
consisting of rapamycin, bevacizumab, and temozolomide is known to treat advanced melanoma [85]. Nano-emulsions are different from liposomes and certainly have enhanced characteristics than others, such as optical clarity, stability, and biodegradability [86]. However, there are challenges to clinical applications of these nano-emulsions as these involve high temperature and pressure and instruments such as homogenizers and microfluidizers that are expensive.

\subsection{Carbon nanoparticles}

Carbon NPs as the name suggests, are based on the element carbon. They have been widely utilized in medical arenas because of optical, mechanical, and electronic properties combined with biocompatibility [87]. Due to their inherent hydrophobic nature, carbon NPs can encapsulate drugs through $\pi-\pi$ stacking [88]. Carbon NPs are further categorized into graphene, carbon nanotubes, fullerenes, carbon nano-horns, and graphyne. Although all these are carbonbased, they vary in their structure, morphology, and properties.

"Graphene" is 2D crystal with sp2-hybridized carbon sheet that holds extraordinary mechanical, electrochemical, and high drug loading properties. Further, based on composition, properties, and composition, graphene can be divided as follows: 1) single-layer graphene, 2) graphene oxide (GO), 3) reduced graphene oxide ( $\mathrm{rGO}$ ), and 4) multi-layer graphene [89]. GO, and rGOs are widely used due to their ability to target hypoxia [90] and irregular angiogenesis in TME [91]. Studies have shown that GO-doxorubicin exhibits higher anti-cancer activities in cellular models of breast cancer [92].

Fullerenes are large carbon-cage molecules composed of carbon allotrope with different conformation types such as sphere, ellipsoid, or tube. They are the most widely studied nanocarriers as they have typical structural, physical, chemical, and electrical properties [93]. These are used in photodynamic therapy as they have triple yield and generate oxygen species due to the presence of extended $\pi$-conjugation and the ability to absorb light [94]. PEGmodified fullerenes showed promising photodynamic effects on tumor cells [95].

Carbon nanotubes (CNTs) are cylindrical tubes, most often considered as rolls of graphene were discovered in the late 1980s. They are classified into two groups: 1) single-walled CNTs and 2) multi-walled CNTs. As they are carbon-based, they can bring upon immune response by interacting with immune cells, thereby suppressing the tumor growth. Traditionally, they have been used as DNA delivery vectors and for thermal ablation therapy. For instance, a fluorescent single-walled CNT with mAb encapsulating doxorubicin is used to target colon cancer cells. Such CNTs form a complex which is effectively engulfed by the cancer cells leading to the intracellular release of doxorubicin, whereas the CNTs are retained in the cytoplasm [96].

\subsection{Quantum dots}

Quantum dots are typically nanometer-scale semiconductors with a broad spectrum of absorption, narrow emission bands, and high photostability, allowing them to be widely used in biological imaging [97]. Based on carbon, these are divided into: 1) graphene quantum dots, 2) Nano-diamond quantum dots, and 3) carbon quantum dots. Besides biological imaging, quantum dots are being actively investigated in cancer treatment. The most commonly used quantum dots is graphene quantum dots due to their inherent biocompatibility and rapid excretion. For example, quantum dots aptamer - doxorubicin conjugate targets prostate cancer cells [98]. However, the deficiency of optimized process in producing quantum dots is the major obstacle 


\subsection{Metallic nanoparticles}

Metallic nanoparticles are commonly explored in "biological imaging" and targeted DDS due to remarkable optical, magnetic, and photothermal properties. Some of the most commonly used metallic NPs are gold NPs, silver NPs, iron-based NPs, and copper NPs. Gold NPs are used as intracellular targeting drug carriers because the size, and surface properties are easily controlled [99]. Moreover, their visible light extinction behavior makes it possible to track NP trajectories in the cells. "Anti-HER2 functionalized gold-on-silica nanoshells" have been shown to aim HER2 positive breast cancer cells [100]. Combidex ${ }^{\circledR}$, an iron oxide NP formulation, is presently in the late-stage clinical testing phase to detect nodal metastases [101]. Feraheme ${ }^{\circledR}$, a ferumoxytol containing iron oxide NP formulation, is used to treat iron deficiency anemia. This is also used to treat nodal metastases in prostate and testicular cancer and was approved by FDA in June 2009 [102, 103].

\subsection{Magnetic nanoparticles}

Magnetic NPs are generally used in MRI imaging, and drug delivery contain metal or metal oxides. These are usually covered with organic substances like polymers and fatty acids to obtain enhanced stability and biocompatibility [104]. LHRH - conjugated superparamagnetic iron oxide NPs are effective in targeting and imaging of breast cancer [105]. Moreover, magnetic NPs are used in magnetic hyperthermia for thermal ablation of cancer cells [106, 107]. Some of the magnetic NPs that are in the market or in the clinical trial phase are Feridex ${ }^{\circledR}$, and Resovist ${ }^{\circledR}$ for liver metastasis and colon cancer [101].

\subsection{Calcium phosphate nanoparticles}

"Calcium phosphate NPs" is biologically compatible, biodegradable, and does not cause any harsh adverse reactions. Hence, they are used as a delivery agent for insulin, growth factors, antibiotics, and contraceptives [108]. They are also used in the delivery of oligonucleotides and plasmid DNA [109]. Calcium phosphate NPs combined with either viral or non-viral vector has been positively used as delivery vectors in cellular gene transfer. A "liposomal nanolipoplex formulation" of calcium and glycerol has shown decreased toxicity and enhanced transfection features $[110,111]$.

\subsection{Silica nanoparticles}

Silica being a significant component of many natural materials, was only studied concerning biology recently. Silica NPs are commonly used to deliver gene by functionalizing the NP surface with amino-silicanes [112]. N- (6 - aminohexyl) - 3 - aminopropyl - trimethoxysilane functionalized silica NPs have shown excellent efficiency in the transfection of Cos-1 cells with minimal toxicity and is now commercially available [113]. Mesoporous silica NPs are considered one of the best drug carriers due to their better pharmacokinetic properties. They have been extensively used in immunotherapy. According to a study, colorectal cancer cells have shown successful uptake of camptothecin-loaded mesoporous silica NPs [114].

\subsection{Cyclodextrin nanosponges}

Cyclodextrins are usually used as stabilizers to increase the drug loading capacity of NPs [115]. Nanosponges are tiny, mesh-like structures [116]. B-cyclodextrin nanosponges loaded with paclitaxel have shown sound cytotoxic effects in MCF-7 cell line culture [117]. Similarly, camptothecin has shown improved solubility and stability when formulated with cyclodextrinbased nanosponges [118]. 


\section{Nanoparticles in Immunotherapy}

The immune system sets an important part in the establishment and development of cancer cells. The advancement of immunotherapy has revolutionized cancer therapy. It is found that NPs not only help in target delivery of chemotherapy but can also be used in combination with immunotherapy. There are several approaches in immunotherapy aimed at activating the immune system against cancer cells [119] by "immune checkpoint blockade therapy", "cancer vaccine therapy", "chimeric antigen receptor (CAR)-T cell therapy", and "immune system modulator therapy" [120]. NP-based immunotherapy includes "nano-vaccines", "aAPCs (artificial antigen presenting cells)", and "immunosuppressed TME targeting".

Nanovaccines specialize in delivering "tumor-associated antigens" and "adjuvants" to antigen presenting cells, such as dendritic cells (DCs) [121]. Moreover, these can also be employed as adjuvants to enhance "APC antigen presentation" and promote DC maturation that leads to the stimulation of cytotoxic T- cells that have anti-tumor function [122, 123]. Liposomes, PLGA NPs, gold NPs re found to have the ability to delivery TAAs into DCs in the cytoplasm [124]. Mesoporous silica, the most used inorganic NP, has exhibited an adjuvant role, leading to immune response stimulation [125]. Artificial APCs interact with MHC- antigen complexes directly which binds to T- cells. They also bind to co-stimulatory molecules that bind to costimulatory receptors leading to T-cell activation [126]. Targeting the immunosuppressed TME is yet another method of using NPs in immunotherapies. This is done by targeting essential cell types in TME such as "tumor-associated macrophages (TAMs)", regulatory T cells, and "myeloid-derived suppressor cells (MDSCs)".

Besides, the combination of chemoimmunotherapy has demonstrated to be a capable approach in cancer therapy. For instance, a study has shown that co-loading Nutlin-3a, which is a chemotherapeutic agent and cytokine GM-CSF, in "spermine-modified acetylated dextran (AcDEX) NPs" improved cytotoxic CD8 $(+) \mathrm{T}$ cells proliferation and activated an immune response [127].

"Programmed cell death protein 1 (PD-1)" and "programmed cell death ligand 1 (PD-L1)" are some of the essential immune checkpoints [128]. Hence immune checkpoint inhibitors are used to target these using NPs. According to a study, conventional immune checkpoint inhibitors of PD-L1/PD-1 displayed inconsistent responses. To enhance the chances and bonding of immune checkpoint inhibitors and immune checkpoints, multivalent poly (amidoamine) dendrimers were used. Usage of these dendrimers not only showed enhanced PD-L1 blockade but also showed improved drug accumulation at the tumor site [129]. 


\section{Nanoparticles in cryosurgery}

Cryosurgery is an advanced practice of freeze- destroying cancer tissue. Although this is less invasive and causes intraoperative bleeding and postoperative complications, certain drawbacks like inadequate freezing capacity and damage to adjacent cells need to be addressed [130]. The rise of nanotechnology has enabled the use of NPs in cryosurgery.

The primary working of nano-cryosurgery is introducing NPs with particular properties into the cancer cells and cause freezing [131]. During this process, ice is formed within the cells, which causes damage to it. This is an important process and can be carried out effectively using NPs. The thermal conductivity property of NPs can be exploited, which significantly freeze the tumor tissue and cause tumor damage [132]. Besides, they cool down rapidly, and it is feasible to regulate the "growth direction" and "direction of the ice ball".

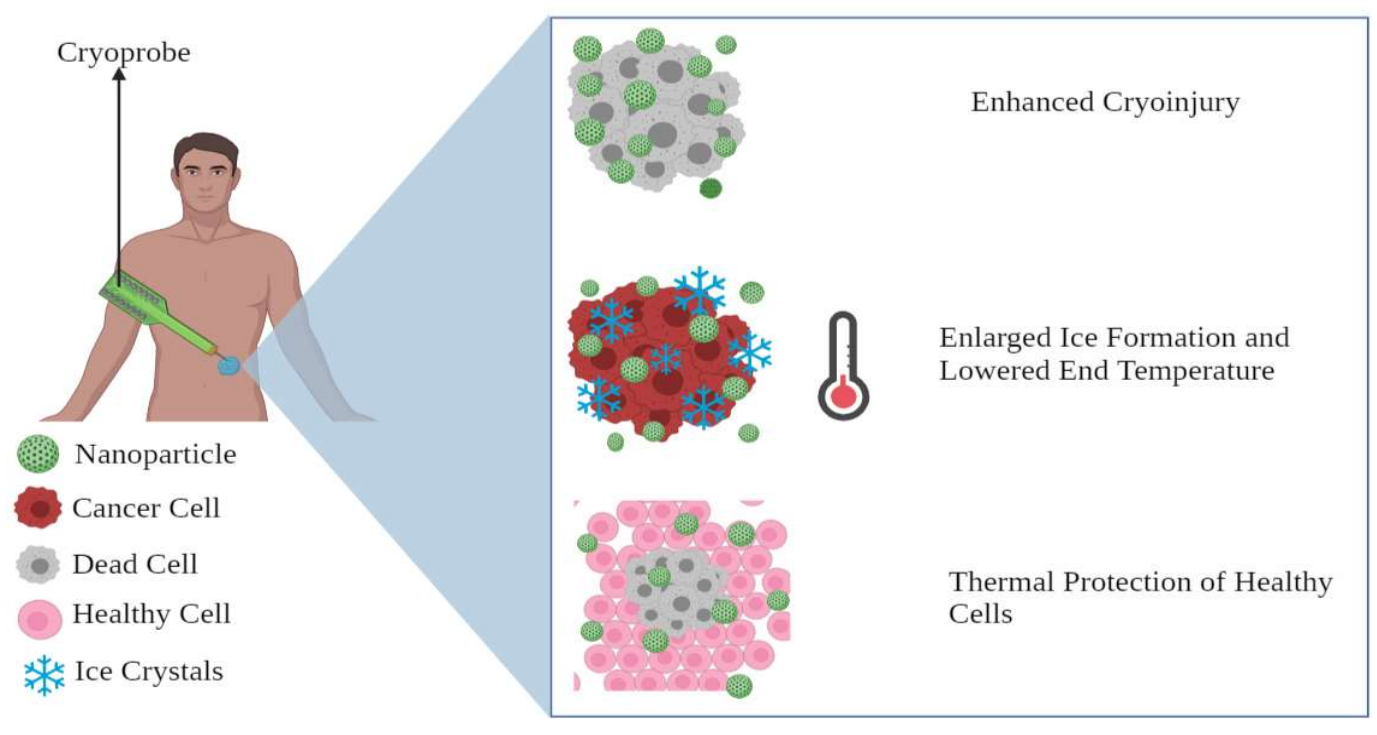

Figure 6: Diagrammatic representation of NPs in cryosurgery.

When the location of the tumor makes it not feasible for cryosurgery or if other adjacent organs are at risk, there are high chances that the freezing can damage healthy tissue. Recently, phase change materials (PMs) made up of NPs are used to protect the adjacent normal healthy tissue during cryosurgery [133]. For instance, liposome-based microencapsulated phase change NPs have shown incredible results in protecting surrounding healthy tissue [134]. These NPs are deemed to possess large latent heat and low thermal conductivity, making them a perfect fit for cryosurgery. 


\section{Mechanism of NPs in overcoming drug resistance}

Drug resistance is one of the chief problems in cancer therapy and management. It prevails across all types of cancer and all possible treatment modalities. Drug resistance is a phenomenon that results when diseases become tolerant to pharmaceutical treatments. Drug resistance can be classified into two types: 1) innate and 2) acquired [135]. Innate resistance usually results from pre-existing mutations in the genes that are involved in the cell growth or apoptosis. Acquired resistance is defined as the type of resistance that is developed after a particular anti-tumor treatment, which may result from the development of new mutations or from alterations in the TME during treatment. Nanoparticles, due to their extraordinary ability to co-encapsulate multiple therapeutic agents, can also be used to overcome cancer-related drug resistance.

\subsection{Targeting Efflux Transporters}

Efflux transporters are classified under the family of "ATP-binding cassette (ABC) transporters". These have a significant role in MDR. The primary function of these transporters is to pump out drugs out of the cell and reduce the concentration. "P-glycoprotein (P-gp)" is one such efflux transporter that is overexpressed by drug-resistant cancer cells $[136,137]$.

Overexpression of P-gp has been linked with inadequate treatment response, especially in breast cancer [138] and ovarian cancer [139]. NPs can be used to tackle efflux pumps. As NPs internalize the cell via "endocytosis" instead of diffusion and release the drug at the "perinuclear site", which is distant from active efflux pumps, NPs can bypass the efflux pumps [140]. Besides, by modifying the control of drug release, such as by utilizing low $\mathrm{pH}$ levels and redox as triggers, NPs can effectively bypass efflux pumps [141, 142].

Combination therapy is yet another method to overcome MDR. NPs can be loaded with multiple drugs within a single drug carrier [143]. Inhibiting efflux transporter expression instead of just dodging them would be another viable option. This can be achieved by building NPs in such a way that it can entrap both efflux pump inhibitors and chemotherapy agents [144]. A recent study positively reflected upon reversing MDR in breast cancer cells by using NPs that co-deliver COX-2 inhibitors and doxorubicin [145]. Similarly, using silica NP that encapsulates miRNA-495 and doxorubicin has proved effective in overcoming drug resistance in lung cancer cells [146]. Another interesting study found out that using NPs in the tumor neovasculature targeting KDR receptors is more effective anti-tumor function than P-gp inhibitor combination therapy. Yet, another way of overcoming drug resistance is by depleting the source of ATP, which is essential for the functioning of ABC transporters. This can be done by targeting mitochondria which leads to a decrease in ATP production.

\subsection{Targeting apoptotic pathway}

Cancer cells proliferate due to faulty apoptotic machinery and upsurge their surivival adding to drug resistance [147]. The faulty apoptotic pathway gets activated by "deregulation of Bcl2 " and "nuclear factor kappa B (NF-kB)". These are most widely investigated anti-apoptotic proteins and can be potentially used as the target for reversing drug resistance. Using a classic process of co-delivery of "Bcl-2 siRNA and chemotherapeutics" by NPs is a way to overcome MDR [148]. NF- $\kappa B$ inhibitors have been used in combination with "pyrrolidine dithiocarbamate (PDTC)" [149] and curcumin [150]. Besides suppressing anti-apoptotic factors, triggering pro-apoptotic factors is an another to fight "apoptotic pathway-mediated drug resistance". For instance, combination of ceramide and paclitaxel is a good example [151]. Ceramide restores the expression of a chief tumor suppressor, p53 protein, by regulating alternative pre-mRNA splicing. Delivering ceramide via NPs is an excellent way to correct the 
p53 missense mutation [152]. Owing to its potential, a combination of ceramide and paclitaxel has shown significant therapeutic efficacy in cancer drug resistance models. Transfecting the p53 gene by cationic SLNs has been reported in lung cancer cases [153]. Similarly, transfecting the p53 gene by PLGA has been carried out in breast cancer cells models that have shown potent induction of apoptosis and inhibition of tumor growth [154].

Some NP-based DDS act by impeding efflux pumps and encouraging apoptosis [155]. A pioneering study conducted to prove both pump and non-pump mediated drug resistance used an "amphiphilic cationic NP" entrapping paclitaxel and Bcl-2 converter gene in drug resistant liver cancer models. NP complex diminished P-gp induced drug efflux and the apoptosis activation. Similarly, co-delivery of "doxorubicin and resveratrol encapsulated in NPs" have shown noteworthy cellular toxicity on doxorubicin resistance breast cancer cells by downregulating the expression of Bcl-2 and NF- $\kappa \mathrm{B}$ thereby initiating apoptosis as well as through the inhibition of efflux transporter expression [156]. A similar study was done on multi drug resistant prostate cancer cells by using folic acid conjugated planetary ball milled NPs encapsulated with resveratrol and docetaxel. This worked by downregulating anti-apoptotic gene expression while inhibiting ABC- transporter markers [157].

\subsection{Targeting Hypoxia}

Hypoxia is yet an additional aspect that backs MDR [158]. Due to abnormal blood vessels in the vicinity of the tumor and due to increasing demand of oxygen by the rapidly growing tumor, some tumor cells are repeatedly in a hypoxic condition. The part og the tumor that is in hypoxic condition often escape from the chemotherapy drugs. Hypoxia creates an oxygen ramp of inside the tumor that intensifies tumor heterogeneity, encouraging a more aggressive phenotype. Moreover, hypoxia condition has been established to facilitate the overexpression of efflux proteins [159]. The major protein, "hypoxia inducible factor $1 \alpha$ (HIF-1 $\alpha$ )" acts a important role. Hence targeting HIF-1 $\alpha$, or silencing HIF-1 $\alpha$ gene is a way to overcome drug resistance. NPs containing HIF-1 $\alpha$ siRNA can be used to reduce hypoxia mediated drug resistance [160]. Instead of directly targeting HIF-1 $\alpha$, indirect inhibition of HIF-1 $\alpha$ signaling can be used. For example, the "PI3K/Akt/mTOR pathway" is known to control the expression of HIF-1 $\alpha$. Inhibition of this pathway effectively downregulates the expression of HIF-1 $\alpha$, which enhances the sensitivity of MDR cells to cancer treatment [161]. NPs like PLGA-PEG and PEGylated and non-PEGylated liposomes can be used effectively. In addition, "heat shock protein 90 (HSP90)" is needed for transcriptional activity of HIF-1 and inhibition of HSP90, which downregulates the expression of HIF-1 $\alpha$ [162]. The HSP90 inhibitor in "17AAG loaded NPs" has dramatically improved MDR in bladder cancer treatment [163]. 


\section{Nanoparticles and proteomics}

When NPs are subjected to the biological system, they are surrounded by cellular and serum proteins which form a structure known as protein corona (PC) [164]. Based on the degree of interaction of thess proteins with the NPs, there are classified into hard corona and soft corona. "Hard corona" is formed when these proteins have high binding affinity towards the NPs. "Soft corona" is produced when these proteins are loosely bound to the NPS. It has been established that the most protein forming a PC first will be eventually substituted by proteins with higher affinities. This is known as Vroman effect [165]. Hence developing the technology that can manufacture NPs with desired properties is essential. Several proteomic approaches such as MS, LC-MS, SDS-PAGE, isothermal microcalorimetry (ITC), etc [166] are being used. PC affects the crosstalk of NP with the biological setting and thereby governs the application and usage of the same in the medical field.

Cancer proteomics studies the number of proteins in cancer cells and serum, which supports in hunting proteins and biomarkers that aids in diagnosis, treatment, and prognosis [167]. It also helps in understanding cancer pathogenesis and drug resistance mechanism. Post-translational modifications (PTMs) play an indispensable part in occurrence, recurrence, and metastasis. Besides using chemotherapy and kinase inhibitors, novel agents like siRNA, mRNA, and gene editing are central therapeutics used with NPs.

\subsection{Nanotechnology for Small Interfering RNA (siRNA) Delivery}

siRNAs are small ds RNA molecules (around 21 nucleotides long) that suppress the expression of genes in the target. This process is known as "RNA interference". A few siRNA-based NPs that are currently under clinical investigations are ALN-TTR01 that is used to target the transthyretin gene to treat transthyretin-mediated amyloidosis, and Atu027, which is a liposomal siRNA which targets protein kinase N3 and TKM-ApoB that known downs the expression of ApoB [168, 169].

\subsection{Nanotechnology for Tumour microRNA Profiling and Delivery}

MicroRNA are a class of endogenous "single-stranded non-coding RNA" molecules that control post transcription gene expression by blocking translation of the target mRNA or repressing protein production by destabilizing mRNA [170]. These are emerging as vital biomarkers that are a significant target for cancer diagnosis, therapy, and treatment. The base priming nature of nucleic acid forms the very foundation for nanotechnology used miRNA profiling techniques. Several profiling techniques use biosensors or surface plasmon resonance imaging techniques in combination with molecular biology enzymatic reactions. Nanotechnology ca be used for the delivery of MicroRNs. For example, biodegradable polycationic prodrug showed promising results in the regulation of polyamine metabolism [171]. MicroRNA loaded polycation-hyaluronic acid NPs of single-chain antibody fragments have shown progressive downregulation of "survivin expression" in high metastatic cancer load in the lung of murine B16F10 melanoma. 


\subsection{DNA Nanotechnology for Cancer Therapy}

DNA-based nanostructures have been synthesized for DNA sensors to detect nucleic acid, DNA coated gold NPs for lead sensing by hybridizing Pb-activated DNAzyme to the linking DNA, scaffolds to organize organics, inorganic, and biomolecules into distinct morphology molecular transporters, and drug delivery.

Table 1. List of nanomedicines for cancer therapy approved by FDA [172 - 175]

\begin{tabular}{|c|c|c|c|c|c|}
\hline Tradename & Material & Drug & Company & Indication & $\begin{array}{l}\text { Year(s) } \\
\text { approved }\end{array}$ \\
\hline Doxil ${ }^{\circledR}$ & $\begin{array}{l}\text { Liposome- } \\
\text { PEG }\end{array}$ & Doxorubicin & Janssen & $\begin{array}{l}\text { MBC, } \\
\text { metastatic } \\
\text { ovarian } \\
\text { cancer }\end{array}$ & 1995 \\
\hline Eligard $®$ & PLGA & $\begin{array}{l}\text { Leuprolide } \\
\text { acetate }\end{array}$ & Tolmar & $\begin{array}{l}\text { Prostate } \\
\text { Cancer }\end{array}$ & 2002 \\
\hline Abraxane ${ }^{\circledR}$ & Albumin & Paclitaxel & Celgene & $\begin{array}{l}\text { Metastatic } \\
\text { breast cancer }\end{array}$ & 2005 \\
\hline $\begin{array}{l}\text { Genexol } \\
\text { PM® }\end{array}$ & mPEG-PLA & Paclitaxel & $\begin{array}{l}\text { Samyang } \\
\text { Corporation }\end{array}$ & $\begin{array}{l}\text { Metastatic } \\
\text { breast cancer }\end{array}$ & 2007 \\
\hline Onivyde ${ }^{\circledR}$ & Liposome & Irinotecan & Merrimack & $\begin{array}{l}\text { Pancreatic } \\
\text { cancer }\end{array}$ & 2015 \\
\hline
\end{tabular}

\section{Advantages of Nanoparticles in Cancer therapy}

The utilization of nanotechnology in diagnosis, treatment and management of cancer has led to a whole new era. NPs, either by active or passive targeting, augment the intracellular concentration of drugs while avoiding toxicity in the healthy tissue. The targeted NPs can be designed and altered as either $\mathrm{pH}$-sensitive or temperature-sensitive to establish and regulate the drug release. The $\mathrm{pH}$-sensitive drug delivery system can deliver drugs within the acidic TME. Similarly, the temperature-sensitive NPs release the drugs in the target site due to changes in temperature brought in by sources like magnetic fields and ultrasound waves. In addition, the "physico-chemical characteristics" of NPs, such as shape, size, molecular mass, and surface chemistry, have a significant part in the targetedDDS. Further, NPs can be modified according to the target and used to target a particular moiety.

Conventional chemotherapy and radiation therapy have several disadvantages concerning efficacy and side effects because of uneven dispersal and cytotoxicity. Therefore, cautious 
dosing is required that effectively kills cancer cells without any significant toxicity. To reach the target site, the drug has to pass several fortifications. Drug metabolism is a very complex process. In physiological conditions, the drug needs to pass TME, RES, BBB, and kidney infiltration. RES or macrophage system is made up of "blood monocytes, macrophages and other immune cells" [176]. MPS in the liver, spleen, or lungs react with the drugs and activate "macrophages or leukocytes" that rapidly remoes the drug. This leads to a short half-life of drug [177]. To overcome this, NPs with "surface modification" such as PEG, bypass this mechanism and increase the "drug half-life". Besides, kidney infiltration is a crucial function in the human body. Proper kidney infiltration thus minimizes the toxicity caused by NPs.

Th brain-blood barrier (BBB) is a specialized protection structure offered to protect the CNS from harmful and toxic agents. "Brain capillary endothelial cells" are arranged in the form of a wall that provides essential nutrients to the brain. Since the primary function of BBB is to block toxic agents to reach the brain, currently available chemotherapy agents for brain cancer are highly limited to intraventricular or intracerebral infusions [178]. However, NPs are known to cross BBB. Now, several approaches such as EPR effect, focused ultrasound, peptidemodified endocytosis, and transcytosis are used to deliver NPs. Glutathione PEGylated liposome encapsulated with methotrexate showed improved methotrexate uptake in rats [179]. Au-NPs are often used as they have proven to help transport drugs to induce apoptosis [180].

NPs being carriers also increase the drug stability by preventing the degradation of the encapsulated cargo. Additionally, large volume of drug can be encapsulated without any chemical reaction. Dry solid dosage forms are more stable than nano liquid products [181]. Stabilizers can be used to enhance the stability. Yet another way to increase stability is to use porous NPs.

Tumour has unique pathophysiology features such as extensive angiogenesis, flawed vascular architecture and defective lymphatic drainage. These features are used by the NPs to target tumour tissue. Due to reduced venous return in tumor tissue and meager lymphatic clearance, NPs are effectively retained. This phenomenon is known as EPR. Similarly, by targeting the adjacent tissues, tumor targeting can be accomplished [182].

NPs can be administered through several routes like oral, nasal, parenteral, intra-ocular etc. NPs have high surface-to-volume ratio and intracellular uptake. Studies have reported that NPs are more effective than microparticles as drug carriers [183]. 


\section{Significant challenges in the clinical application of nanoparticles}

At present, as nanotechnology has bloomed, the amount of knowledge and research put into nanoparticles has steeply raised. But only a few of them actually make it up to clinical trials. Most of them only halt at in vivo and in vitro stage. Each individual nano-formulation has particular challenges in their clinical translation, but most NPs face similar challenges that can be divided into biological, technological, and study-design related.

Biological challenges include lack of routes of administration, tempering biodistribution, the channel of NPs across the biological barriers, their degradation, and toxicity [184]. NPs are usually injected via intravenous injections directly into the blood which takes away NPs, making it challenging to stay and interact with the target site. As a result, a high concentration drug is used which might not provide desired therapeutic effects [185]. However, magnetic NPs can be used to overcome this as many in vivo and in vitro studies have proved the usage of 3D magnetic flied to control the movement of NPs against blood flow. But, the effect of magnetic fields on the human body, crosstalk between magnetic fields, and a large number of NPs have to be researched upon.

Controlling biological fate of NPs is very hard and needs a lot of focus. Even though NPs are made up of biosafety materials and are modulated accordingly to increase the retention time and half-life, there runs a risk of lung, liver and kidney damage. Some factors that govern toxicity are surface area, particle size and shape, solubility, and agglomeration [186]. NPs have shown greater deposition in lung with inflammatory, oxidative and cytotoxic effects [187]. Studies reveal that healthy cells often suffer from free radicals generated by NPs [188]. Fabricating NPs with more biocompatible substances like chitosan and materials that disintegrate after near infrared light irradiation may be potential solutions.

Another tricky challenge is avoiding the "mononuclear phagocytic system (MPS)". In biological fluids, NPs adsorb proteins to produce PC, which attacks MPS to uptake NPs. To escape this, NPs have been coated with materials that prevent the formation of the protein corona. However, they have not shown any significant results. Designing NPs that target "macrophages" and using those as new drug vehicles can be pitched to overcomes this problem. Currently, preventing macrophage recruitment, depleting and reprograming TAMs, and obstructing "CD47-SIRP $\alpha$ pathways" are commonly used strategies [189].

Technological challenges of NPs include scale-up synthesis, equal optimization, and performance predictions. These are very crucial in safeguarding the clinical success of NPs. Most of the NPs that are used in vivo and in vitro studies are usually produced in minor batches, and scale-up for huge quantities is not constantly feasible given instrumentation and other reasons. The lead clinical candidates that prove to be the best in animal models are not systematically designed optimized. To overcomes this, we can use certain methods that can test numerous nano-formulation and by selective iterations selecting a single optimized formulation [190-192]. However, such hits shouldn't be introduced directly in human testing. Predicting nanoparticle efficacy and performance is hard and replicating the in vivo results in human trials is a herculean task. Computational or theoretical modelling along with experimental results can be designed to imitate physiological tissue and surrounding. For instance, organs-on-chips are being actively studied upon and can improve NP predictions of efficacy and performance. 
Study-design challenges like study size, intent, and timing of NP therapies during the therapy impact significantly during clinical studies. Most of the studies revolve around "cell and animal models" that may not provide comprehensible results in human trials. Therefore, the usage of a single model is tough to imitate natural reactions in the human body. In addition, "models of cancer metastasis" should be actively researched as metastasis is one of the significant properties of cancer. Moreover, $\mathrm{N}=1$ clinical studies will be required if we focus on personalized medicine. This needs to count in many factors such as genetic, environmental, past medical history etc [193]. Another major challenge is that NPs are never used as first-line therapies. Although we have effectively approved nano-formulations, they are usually saved for further treatment lines if disease progression is found. In the clinical trial scenario. Most of the patients have either had progressed on multiple lines of therapies or have gained drug resistance. These situations often skew the clinical trial results and lessen the chance of NP treatment to benefit those who are likely still treatable.

\section{Conclusion and future perspective}

Nanotechnology has shown a promising new era of cancer treatment by delivering small molecules for cancer detection, diagnosis, and therapy. Cancer therapies based on the exceptional features of NPs are being vastly used in the clinical setting of several cancer types. Compared to conventional drugs, NP-based DDS are linked with enhanced pharmacokinetics, biocompatibility, tumour targeting and stability. Moreover, NPs provide an excellent platform for combination therapy which helps in overcoming MDR. With increasing research several types of NPs such as polymeric NPs, metallic NPs, hybrid NPs, etc. have shown improved efficacy of drug delivery. Researchers must be well attentive of the features of the nominated nanoplatforms and the properties of therapeutic agents. However, there are certain limitations like deficiency of in vitro models that precisely replicate in vivo stage, immunotoxicity, the long-term toxicity, and neurotoxicity. Although "nano-vaccines" and "artificial APCs" have proved improved efficacy compared to conventional immunotherapy, the clinical efficacy is substandard. The safety and tolerance of these new modalities should to be inspected. Additionally, developing "immunomodulatory factor-loaded NPs" may advance the efficiency of vaccines for immunotherapy.

This is an emerging area, and is anticipated that with growth in proteomics research on the "mechanism of cancer origin, MDR, occurrence", more NP-based drugs can be exploited. Compared to the mammoth amount of investigations, only a few NP-based drugs are actually in use, a few others in clinical trials, and most in the exploratory stage. For rational nanotechnology design, more efforts must be reserved in "understanding toxicity, cellular and physiological factors that regulate NP-based drug delivery, EPR, and PC mechanism" in the human body. Based on the evidence cited above, we presuppose that the revolution in clinical translation for NP-based cancer therapy will be attained with nanotechnology and cancer therapy development. 


\section{References:}

1. Wu, S., Zhu, W., Thompson, P., \& Hannun, Y. A. (2018). Evaluating intrinsic and nonintrinsic cancer risk factors. Nature communications, 9(1), 3490. https://doi.org/10.1038/s41467-018-05467-z

2. Anand, P., Kunnumakkara, A. B., Sundaram, C., Harikumar, K. B., Tharakan, S. T., Lai, O. S., Sung, B., \& Aggarwal, B. B. (2008). Cancer is a preventable disease that requires major lifestyle changes. Pharmaceutical research, 25(9), 2097-2116. https://doi.org/10.1007/s11095-008-9661-9

3. Cancer Facts \& Figures $2021 \mid$ American Cancer Society. (n.d.). Www.cancer.org. https://www.cancer.org/research/cancer-facts-statistics/all-cancer-facts-

figures/cancer-facts-figures-

2021.html\#: : text=The $\% 20$ Facts $\% 20 \% 26 \% 20$ Figures $\% 20$ annual $\% 20$ report $\% 20$ provi des $\% 3 \mathrm{~A} \% 201$

4. Park, W., Heo, YJ. \& Han, D.K. New opportunities for nanoparticles in cancer immunotherapy. Biomater Res 22, 24 (2018). https://doi.org/10.1186/s40824-018$\underline{0133-y}$

5. Jovčevska, I., \& Muyldermans, S. (2020). The Therapeutic Potential of Nanobodies. BioDrugs : clinical immunotherapeutics, biopharmaceuticals and gene therapy, 34(1), 11-26. https://doi.org/10.1007/s40259-019-00392-z

6. Zitvogel, L., Apetoh, L., Ghiringhelli, F., \& Kroemer, G. (2008). Immunological aspects of cancer chemotherapy. Nature reviews. Immunology, 8(1), 59-73. https://doi.org/10.1038/nri2216

7. Chan, H.-K., \& Ismail, S. (2014). Side Effects of Chemotherapy among Cancer Patients in a Malaysian General Hospital: Experiences, Perceptions and Informational Needs from Clinical Pharmacists. Asian Pacific Journal of Cancer Prevention, 15 (13), 5305-5309. https://doi.org/10.7314/apjcp.2014.15.13.5305

8. Mahapatro, A., Singh, D.K. Biodegradable nanoparticles are excellent vehicle for site directed in-vivo delivery of drugs and vaccines. J Nanobiotechnol 9, 55 (2011). https://doi.org/10.1186/1477-3155-9-55

9. Kroemer, G., Zitvogel, L. The breakthrough of the microbiota. Nat Rev Immunol 18, 87-88 (2018). https://doi.org/10.1038/nri.2018.4

10. Rosenberg, S. A., Restifo, N. P., Yang, J. C., Morgan, R. A., \& Dudley, M. E. (2008). Adoptive cell transfer: a clinical path to effective cancer immunotherapy. Nature reviews. Cancer, 8(4), 299-308. https://doi.org/10.1038/nrc2355

11. Melero, I., Rouzaut, A., Motz, G. T., \& Coukos, G. (2014). T-cell and NK-cell infiltration into solid tumors: a key limiting factor for efficacious cancer immunotherapy. Cancer discovery, 4(5), 522-526. https://doi.org/10.1158/21598290.CD-13-0985

12. Lacouture, M., \& Sibaud, V. (2018). Toxic Side Effects of Targeted Therapies and Immunotherapies Affecting the Skin, Oral Mucosa, Hair, and Nails. American journal of clinical dermatology, 19(Suppl 1), 31-39. https://doi.org/10.1007/s40257-018-0384$\underline{3}$

13. Ankita Dadwal, Ashish Baldi \& Raj Kumar Narang (2018) Nanoparticles as carriers for drug delivery in cancer, Artificial Cells, Nanomedicine, and Biotechnology, 46:sup2, 295-305, DOI: 10.1080/21691401.2018.1457039

14. Palazzolo, S., Bayda, S., Hadla, M., Caligiuri, I., Corona, G., Toffoli, G., \& Rizzolio, F. (2018). The Clinical Translation of Organic Nanomaterials for Cancer Therapy: A Focus on Polymeric Nanoparticles, Micelles, Liposomes and Exosomes. Current 
medicinal chemistry, 25(34),

$4224-4268$. https://doi.org/10.2174/0929867324666170830113755

15. Li, W., Zhang, H., Assaraf, Y. G., Zhao, K., Xu, X., Xie, J., Yang, D. H., \& Chen, Z. S. (2016). Overcoming ABC transporter-mediated multidrug resistance: Molecular mechanisms and novel therapeutic drug strategies. Drug resistance updates : reviews and commentaries in antimicrobial and anticancer chemotherapy, 27, 14-29. https://doi.org/10.1016/j.drup.2016.05.001

16. Boisseau, P., \& Loubaton, B. (2011, September 1). Nanomedicine, nanotechnology in medicine. https://www.sciencedirect.com/science/article/pii/S1631070511001538

17. Laurent, S., Forge, D., Port, M., Roch, A., Robic, C., Vander Elst, L., \& Muller, R. (2008, June 11). Magnetic iron oxide nanoparticles: synthesis, stabilization, vectorization, physicochemical characterizations, and biological applications. Https://Pubs.Acs.Org/Doi/10.1021/Cr068445e.

https://www.academia.edu/1082933/Magnetic_iron_oxide_nanoparticles_synthesis_st abilization_vectorization_physicochemical_characterizations_and_biological_applicat ions

18. Tiwari, J. N. (2011, August 14). Zero-dimensional, one-dimensional, two-dimensional and three-dimensional nanostructured materials for advanced electrochemical energy devices.

Https://Www.Academia.Edu/32389141/Zero_dimensional_one_dimensional_two_di mensional_and_three_dimensional_nanostructured_materials_for_advanced_electroc hemical_energy_devices.

https://www.academia.edu/32389141/Zero_dimensional_one_dimensional_two_dime nsional_and_three_dimensional_nanostructured_materials_for_advanced_electroche mical_energy_devices

19. Shin, WK., Cho, J., Kannan, A. et al. Cross-linked Composite Gel Polymer Electrolyte using Mesoporous Methacrylate-Functionalized $\mathrm{SiO}_{2}$ Nanoparticles for Lithium-Ion Polymer Batteries. Sci Rep 6, 26332 (2016). https://doi.org/10.1038/srep26332

20. Prokop, A., \& Davidson, J. M. (2008). Nanovehicular intracellular delivery systems. Journal of pharmaceutical sciences, 97(9), 3518-3590. https://doi.org/10.1002/jps.21270

21. Yang, Q., Jones, S., Parker, C., Zamboni, W., Bear, J., \& Lai, S. (2014, February 12). Evading Immune Cell Uptake and Clearance Requires PEG Grafting at Densities Substantially Exceeding the Minimum for Brush Conformation. Https://Pubs.Acs.Org/Doi/10.1021/Mp400703d.

https://pubs.acs.org/doi/10.1021/mp400703d

22. Shafey, A. (2020). Green sysnthesis of metal and metal oxide nanoparticles from plant leaf extracts and their applications: A review. Green Processing and Synthesis, 9(1), 304-339. http://doi.org/10.1515/gps-2020-0031

23. Lassalle, Veronica \& Ferreira, María. (2007). PLA Nano- and Microparticles for Drug Delivery: An Overview of the Methods of Preparation. Macromolecular bioscience. 7. 767-83. 10.1002/mabi.200700022.

24. Omidi, Y., \& Barar, J. (2014). Targeting tumor microenvironment: crossing tumor interstitial fluid by multifunctional nanomedicines. BioImpacts : BI, 4(2), 55-67. https://doi.org/10.5681/bi.2014.021

25. Barar, J., \& Omidi, Y. (2013). Dysregulated pH in Tumor Microenvironment Checkmates Cancer Therapy. BioImpacts : BI, 3(4), 149-162. https://doi.org/10.5681/bi.2013.036 
26. Matsumura, Yasuhiro \& Maeda, Hiroshi. (1987). A New Concept for Macromolecular Therapeutics in Cancer Chemotherapy: Mechanism of Tumoritropic Accumulation of Proteins and the Antitumor Agent Smancs A New Concept for Macromolecular Therapeutics in Cancer Chemotherapy: Mechanism of Tumoritropic Accum. Cancer research. 46. 6387-92.

27. Torchilin V. (2011). Tumor delivery of macromolecular drugs based on the EPR effect. Advanced drug delivery reviews, 63(3), 131-135. https://doi.org/10.1016/j.addr.2010.03.011

28. Bates, D. O., Hillman, N. J., Williams, B., Neal, C. R., \& Pocock, T. M. (2002). Regulation of microvascular permeability by vascular endothelial growth factors. Journal of anatomy, 200(6), 581-597. https://doi.org/10.1046/j.14697580.2002.00066.x

29. Jain R. K. (1998). The next frontier of molecular medicine: delivery of therapeutics. Nature medicine, 4(6), 655-657. https://doi.org/10.1038/nm0698-655

30. Hobbs, S. K., Monsky, W. L., Yuan, F., Roberts, W. G., Griffith, L., Torchilin, V. P., \& Jain, R. K. (1998). Regulation of transport pathways in tumor vessels: role of tumor type and microenvironment. Proceedings of the National Academy of Sciences of the United States of America, 95(8), 4607-4612. https://doi.org/10.1073/pnas.95.8.4607

31. Melody A. Swartz and Mark E. FleuryInstitute of Bioengineering. (2007). Interstitial Flow and Its Effects in Soft Tissues. Retrieved July 29, 2021, from https://www.annualreviews.org/doi/full/10.1146/annurev.bioeng.9.060906.151850

32. Padera, T. P., Stoll, B. R., Tooredman, J. B., Capen, D., di Tomaso, E., \& Jain, R. K. (2004). Pathology: cancer cells compress intratumour vessels. Nature, 427(6976), 695. https://doi.org/10.1038/427695a

33. Attia, M. F., Anton, N., Wallyn, J., Omran, Z., \& Vandamme, T. F. (2019, May 03). An overview of active and passive targeting strategies to improve the nanocarriers efficiency to tumour sites. Retrieved July 29, 2021, from https://onlinelibrary.wiley.com/doi/full/10.1111/jphp.13098

34. Pelicano, H., Martin, D. S., Xu, R. H., \& Huang, P. (2006). Glycolysis inhibition for anticancer treatment. Oncogene, 25(34), 4633-4646. https://doi.org/10.1038/sj.onc.1209597

35. Lim, E. K., Chung, B. H., \& Chung, S. J. (2018). Recent Advances in pH-Sensitive Polymeric Nanoparticles for Smart Drug Delivery in Cancer Therapy. Current drug targets, 19(4), 300-317. https://doi.org/10.2174/1389450117666160602202339

36. Miele, E., Spinelli, G. P., Miele, E., Tomao, F., \& Tomao, S. (2009). Albumin-bound formulation of paclitaxel (Abraxane ABI-007) in the treatment of breast cancer. International journal of nanomedicine, 4, 99-105. https://doi.org/10.2147/ijn.s3061

37. D, K., S, K., H, K., S, S., J, K., K, P., . . D, H. (2007, December 1). Multicenter phase II trial of Genexol-PM, a novel Cremophor-free, polymeric micelle formulation of paclitaxel, with cisplatin in patients with advanced non-small-cell lung cancer. Retrieved July 29, 2021, from https://www.annalsofoncology.org/article/S09237534(19)40408-0/fulltext

38. Mukwaya G., Forssen E.A., Schmidt P., Ross M. (1998) DaunoXome® (Liposomal Daunorubicin) for First-Line Treatment of Advanced, HIV-Related Kaposi's Sarcoma. In: Woodle M.C., Storm G. (eds) Long Circulating Liposomes: Old Drugs, New Therapeutics. Biotechnology Intelligence Unit. Springer, Berlin, Heidelberg. https://doi.org/10.1007/978-3-662-22115-0 10

39. Peer, Dan, et al. "Nanocarriers as an Emerging Platform for Cancer Therapy." Nature Nanotechnology, vol. 2, no. 12, Dec. 2007, pp. 751-760, 
www.nature.com/articles/nnano.2007.387, 10.1038/nnano.2007.387. Accessed 18 Dec. 2019.

40. Kamaly, N., Xiao, Z., Valencia, P. M., Radovic-Moreno, A. F., \& Farokhzad, O. C. (2012). Targeted polymeric therapeutic nanoparticles: design, development and clinical translation. Chemical Society reviews, 41(7), 2971-3010. https://doi.org/10.1039/c2cs15344k

41. Byrne, J. D., Betancourt, T., \& Brannon-Peppas, L. (2008). Active targeting schemes for nanoparticle systems in cancer therapeutics. Advanced drug delivery reviews, 60(15), 1615-1626. https://doi.org/10.1016/j.addr.2008.08.005

42. Saha, R. N., Vasanthakumar, S., Bende, G., \& Snehalatha, M. (2010). Nanoparticulate drug delivery systems for cancer chemotherapy. Molecular membrane biology, 27(7), 215-231. https://doi.org/10.3109/09687688.2010.510804

43. Amreddy, N., Muralidharan, R., Babu, A., Mehta, M., Johnson, E. V., Zhao, Y. D., Munshi, A., \& Ramesh, R. (2015). Tumor-targeted and pH-controlled delivery of doxorubicin using gold nanorods for lung cancer therapy. International journal of nanomedicine, 10, 6773-6788. https://doi.org/10.2147/IJN.S93237

44. Santi, M., Maccari, G., Mereghetti, P., Voliani, V., Rocchiccioli, S., Ucciferri, N., Luin, S., \& Signore, G. (2017). Rational Design of a Transferrin-Binding Peptide Sequence Tailored to Targeted Nanoparticle Internalization. Bioconjugate chemistry, 28(2), 471480. https://doi.org/10.1021/acs.bioconjchem.6b00611

45. WARBURG O. (1956). On the origin of cancer cells. Science (New York, N.Y.), 123(3191), 309-314. https://doi.org/10.1126/science.123.3191.309

46. Chan, H.-K., \& Ismail, S. (2014). Side Effects of Chemotherapy among Cancer Patients in a Malaysian General Hospital: Experiences, Perceptions and Informational Needs from Clinical Pharmacists. Asian Pacific Journal of Cancer Prevention, 15 (13), 5305-5309. https://doi.org/10.7314/apjcp.2014.15.13.5305

47. Jiang, W., Kim, B. Y., Rutka, J. T., \& Chan, W. C. (2008). Nanoparticle-mediated cellular response is size-dependent. Nature nanotechnology, 3(3), 145-150. https://doi.org/10.1038/nnano.2008.30

48. Reuveni, T., Motiei, M., Romman, Z., Popovtzer, A., \& Popovtzer, R. (2011). Targeted gold nanoparticles enable molecular CT imaging of cancer: an in vivo study. International journal of nanomedicine, 6, 2859-2864. https://doi.org/10.2147/IJN.S25446

49. Reynolds, J. G., Geretti, E., Hendriks, B. S., Lee, H., Leonard, S. C., Klinz, S. G., ... \& Wickham, T. J. (2012). HER2-targeted liposomal doxorubicin displays enhanced antitumorigenic effects without associated cardiotoxicity. Toxicology and applied pharmacology, 262(1), 1-10

50. Pan, H., Myerson, J. W., Hu, L., Marsh, J. N., Hou, K., Scott, M. J., Allen, J. S., Hu, G., San Roman, S., Lanza, G. M., Schreiber, R. D., Schlesinger, P. H., \& Wickline, S. A. (2013). Programmable nanoparticle functionalization for in vivo targeting. FASEB journal : official publication of the Federation of American Societies for Experimental Biology, 27(1), 255-264. https://doi.org/10.1096/fj.12-218081

51. Low, P. S., \& Kularatne, S. A. (2009). Folate-targeted therapeutic and imaging agents for cancer. Current opinion in chemical biology,13(3), 256-262. https://doi.org/10.1016/j.cbpa.2009.03.022

52. Muralidharan, R., Babu, A., Amreddy, N., Basalingappa, K., Mehta, M., Chen, A., Zhao, Y. D., Kompella, U. B., Munshi, A., \& Ramesh, R. (2016). Folate receptortargeted nanoparticle delivery of HuR-RNAi suppresses lung cancer cell proliferation and migration. Journal of nanobiotechnology, 14(1), 47. https://doi.org/10.1186/s12951-016-0201-1 
53. Samadian, H., Hosseini-Nami, S., Kamrava, S. K., Ghaznavi, H., \& Shakeri-Zadeh, A. (2016). Folate-conjugated gold nanoparticle as a new nanoplatform for targeted cancer therapy. Journal of cancer research and clinical oncology, 142(11), 2217-2229. https://doi.org/10.1007/s00432-016-2179-3

54. Amreddy, N., Babu, A., Muralidharan, R., Panneerselvam, J., Srivastava, A., Ahmed, R., Mehta, M., Munshi, A., \& Ramesh, R. (2018). Recent Advances in NanoparticleBased Cancer Drug and Gene Delivery. Advances in cancer research, 137, 115-170. https://doi.org/10.1016/bs.acr.2017.11.003

55. Masood F. (2016). Polymeric nanoparticles for targeted drug delivery system for cancer therapy. Materials science \& engineering. C, Materials for biological applications, 60 , 569-578. https://doi.org/10.1016/j.msec.2015.11.067

56. Vijayan, V., Reddy, K. R., Sakthivel, S., \& Swetha, C. (2013). Optimization and charaterization of repaglinide biodegradable polymeric nanoparticle loaded transdermal patchs: in vitro and in vivo studies. Colloids and surfaces. B, Biointerfaces, 111, 150-155. https://doi.org/10.1016/j.colsurfb.2013.05.020

57. Elsabahy, M., \& Wooley, K. L. (2012). Design of polymeric nanoparticles for biomedical delivery applications. Chemical Society reviews, 41(7), 2545-2561. https://doi.org/10.1039/c2cs15327k

58. Andronescu, E., \& Grumezescu, A. (2017, March 24). Nanostructures for Drug Delivery. $\quad$ Retrieved July 29, 2021, from https://www.elsevier.com/books/nanostructures-for-drug-delivery/andronescu/978-0323-46143-6

59. Bernardi, A., Braganhol, E., Jäger, E., Figueiró, F., Edelweiss, M. I., Pohlmann, A. R., Guterres, S. S., \& Battastini, A. M. (2009). Indomethacin-loaded nanocapsules treatment reduces in vivo glioblastoma growth in a rat glioma model. Cancer letters, 281(1), 53-63. https://doi.org/10.1016/j.canlet.2009.02.018

60. Wang, X., Yang, L., Chen, Z. G., \& Shin, D. M. (2008). Application of nanotechnology in cancer therapy and imaging. CA: a cancer journal for clinicians, 58(2), 97-110. https://doi.org/10.3322/CA.2007.0003

61. Kim K. Y. (2007). Nanotechnology platforms and physiological challenges for cancer therapeutics. Nanomedicine : nanotechnology, biology, and medicine, 3(2), 103-110. https://doi.org/10.1016/j.nano.2006.12.002

62. Lim, J., Kostiainen, M., Maly, J., da Costa, V. C., Annunziata, O., Pavan, G. M., \& Simanek, E. E. (2013). Synthesis of large dendrimers with the dimensions of small viruses. Journal of the American Chemical Society, 135(12), 4660-4663. https://doi.org/10.1021/ja400432e

63. Lo, S. T., Kumar, A., Hsieh, J. T., \& Sun, X. (2013). Dendrimer nanoscaffolds for potential theranostics of prostate cancer with a focus on radiochemistry. Molecular pharmaceutics, 10(3), 793-812. https://doi.org/10.1021/mp3005325

64. Kukowska-Latallo, J. F., Candido, K. A., Cao, Z., Nigavekar, S. S., Majoros, I. J., Thomas, T. P., . . Baker, J. R. (2005, June 15). Nanoparticle Targeting of Anticancer Drug Improves Therapeutic Response in Animal Model of Human Epithelial Cancer. Retrieved from https://cancerres.aacrjournals.org/content/65/12/5317

65. Sievers, E. L., \& Senter, P. D. (2013). Antibody-drug conjugates in cancer therapy. Annual review of medicine, 64, 15-29. https://doi.org/10.1146/annurev-med050311-201823

66. Abedin, M. R., Powers, K., Aiardo, R., Barua, D., \& Barua, S. (2021). Antibody-drug nanoparticle induces synergistic treatment efficacies in HER2 positive breast cancer cells. Scientific reports, 11(1), 7347. https://doi.org/10.1038/s41598-021-86762-6 
67. György, B., Szabó, T. G., Pásztói, M., Pál, Z., Misják, P., Aradi, B., László, V., Pállinger, E., Pap, E., Kittel, A., Nagy, G., Falus, A., \& Buzás, E. I. (2011). Membrane vesicles, current state-of-the-art: emerging role of extracellular vesicles. Cellular and molecular life sciences : CMLS, 68(16), 2667-2688. https://doi.org/10.1007/s00018$\underline{\text { 011-0689-3 }}$

68. Raposo, G., \& Stoorvogel, W. (2013). Extracellular vesicles: exosomes, microvesicles, and friends. The Journal of cell biology,200(4), 373-383. https://doi.org/10.1083/jcb.201211138

69. Hadla, M., Palazzolo, S., Corona, G., Caligiuri, I., Canzonieri, V., Toffoli, G., \& Rizzolio, F. (2016). Exosomes increase the therapeutic index of doxorubicin in breast and ovarian cancer mouse models. Nanomedicine (London, England), 11(18), 24312441. https://doi.org/10.2217/nnm-2016-0154

70. Wei, W., Ao, Q., Wang, X., Cao, Y., Liu, Y., Zheng, S. G., \& Tian, X. (2021). Mesenchymal Stem Cell-Derived Exosomes: A Promising Biological Tool in Nanomedicine. Frontiers in pharmacology, 11, 590470. https://doi.org/10.3389/fphar.2020.590470

71. D. Michiel Pegtel1 and Stephen J. Gould21Amsterdam UMC. (2019, June 20). Exosomes. $\quad$ Retrieved July 29, 2021, from https://www.annualreviews.org/doi/abs/10.1146/annurev-biochem-013118-111902

72. Samad, A., Sultana, Y., \& Aqil, M. (2007). Liposomal drug delivery systems: an update review. Current drug delivery, 4(4), 297-305. https://doi.org/10.2174/156720107782151269

73. Visht, S., Awasthi, R., Rai, R., \& Srivastav, P. (2014). Development of dehydrationrehydration liposomal system using film hydration technique followed by sonication. Current drug delivery, 11(6), 763-770. https://doi.org/10.2174/1567201811666140910122945

74. Allen, T. M., \& Cullis, P. R. (2013). Liposomal drug delivery systems: from concept to clinical applications. Advanced drug delivery reviews, 65(1), 36-48. https://doi.org/10.1016/j.addr.2012.09.037

75. Zhang, L., Gu, F. X., Chan, J. M., Wang, A. Z., Langer, R. S., \& Farokhzad, O. C. (2008). Nanoparticles in medicine: therapeutic applications and developments. Clinical pharmacology and therapeutics, 83(5), 761-769. https://doi.org/10.1038/sj.clpt.6100400

76. Wang, X., Liu, X., Li, Y., Wang, P., Feng, X., Liu, Q., Yan, F., \& Zheng, H. (2017). Sensitivity to antitubulin chemotherapeutics is potentiated by a photoactivable nanoliposome. Biomaterials, 141, $50-62$. https://doi.org/10.1016/j.biomaterials.2017.06.034

77. Ferrari M. (2005). Cancer nanotechnology: opportunities and challenges. Nature reviews. Cancer, 5(3), 161-171. https://doi.org/10.1038/nrc1566

78. Hofheinz, R. D., Gnad-Vogt, S. U., Beyer, U., \& Hochhaus, A. (2005). Liposomal encapsulated anti-cancer drugs. Anti-cancer drugs, 16(7), 691-707. https://doi.org/10.1097/01.cad.0000167902.53039.5a

79. Uner, M., \& Yener, G. (2007). Importance of solid lipid nanoparticles (SLN) in various administration routes and future perspectives. International journal of nanomedicine, 2(3), 289-300.

80. Ali, E. S., Sharker, S. M., Islam, M. T., Khan, I. N., Shaw, S., Rahman, M. A., Uddin, S. J., Shill, M. C., Rehman, S., Das, N., Ahmad, S., Shilpi, J. A., Tripathi, S., Mishra, S. K., \& Mubarak, M. S. (2021). Targeting cancer cells with nanotherapeutics and nanodiagnostics: Current status and future perspectives. Seminars in cancer biology, 69, 52-68. https://doi.org/10.1016/j.semcancer.2020.01.011 
81. Lu, B., Xiong, S. B., Yang, H., Yin, X. D., \& Chao, R. B. (2006). Solid lipid nanoparticles of mitoxantrone for local injection against breast cancer and its lymph node metastases. European journal of pharmaceutical sciences : official journal of the European Federation for Pharmaceutical Sciences, 28(1-2), 86-95. https://doi.org/10.1016/j.ejps.2006.01.001

82. Ma, P., Dong, X., Swadley, C. L., Gupte, A., Leggas, M., Ledebur, H. C., \& Mumper, R. J. (2009). Development of idarubicin and doxorubicin solid lipid nanoparticles to overcome Pgp-mediated multiple drug resistance in leukemia. Journal of biomedical nanotechnology, 5(2), 151-161. https://doi.org/10.1166/jbn.2009.1021

83. Jaiswal, M., Dudhe, R., \& Sharma, P. K. (2015). Nanoemulsion: an advanced mode of drug delivery system. 3 Biotech, 5(2), 123-127. https://doi.org/10.1007/s13205-0140214-0

84. Du, M., Yang, Z., Lu, W., Wang, B., Wang, Q., Chen, Z., Chen, L., Han, S., Cai, T., \& Cai, Y. (2020). Design and development of spirulina polysaccharide-loaded nanoemulsions with improved the antitumor effects of paclitaxel. Journal of microencapsulation, 37(6), 403-412. https://doi.org/10.1080/02652048.2020.1767224

85. Dianzani, C., Monge, C., Miglio, G., Serpe, L., Martina, K., Cangemi, L., . . Battaglia, L. (2020, May 09). Nanoemulsions as Delivery Systems for Poly-Chemotherapy Aiming at Melanoma Treatment. Retrieved from https://www.mdpi.com/2072$6694 / 12 / 5 / 1198$

86. Gorain, B., Choudhury, H., Nair, A. B., Dubey, S. K., \& Kesharwani, P. (2020). Theranostic application of nanoemulsions in chemotherapy. Drug discovery today, 25(7), 1174-1188. https://doi.org/10.1016/j.drudis.2020.04.013

87. Ou, L., Song, B., Liang, H., Liu, J., Feng, X., Deng, B., . . Shao, L. (2016, October 31). Toxicity of graphene-family nanoparticles: A general review of the origins and mechanisms. Retrieved July 29, 2021, from https://particleandfibretoxicology.biomedcentral.com/articles/10.1186/s12989-016$\underline{0168-y}$

88. Krishna, K. V., Ménard-Moyon, C., Verma, S., \& Bianco, A. (2013). Graphene-based nanomaterials for nanobiotechnology and biomedical applications. Nanomedicine (London, England), 8(10), 1669-1688. https://doi.org/10.2217/nnm.13.140

89. Liu, J., Dong, J., Zhang, T., \& Peng, Q. (2018). Graphene-based nanomaterials and their potentials in advanced drug delivery and cancer therapy. Journal of controlled release : official journal of the Controlled Release Society, 286, 64-73. https://doi.org/10.1016/j.jconrel.2018.07.034

90. Tao, Y., , Zhu, L., , Zhao, Y., , Yi, X., , Zhu, L., , Ge, F., , Mou, X., , Chen, L., , Sun, L., , \& Yang, K., (2018). Nano-graphene oxide-manganese dioxide nanocomposites for overcoming tumor hypoxia and enhancing cancer radioisotope therapy. Nanoscale, 10(11), 5114-5123. https://doi.org/10.1039/c7nr08747k

91. Zhang, X., Tian, W., Cai, X., Wang, X., Dang, W., Tang, H., Cao, H., Wang, L., \& Chen, T. (2013). Hydrazinocurcumin Encapsuled nanoparticles "re-educate" tumorassociated macrophages and exhibit anti-tumor effects on breast cancer following STAT3 suppression. PloS one, 8(6), e65896. https://doi.org/10.1371/journal.pone.0065896

92. Fiorillo, M., Verre, A. F., Iliut, M., Peiris-Pagés, M., Ozsvari, B., Gandara, R., Cappello, A. R., Sotgia, F., Vijayaraghavan, A., \& Lisanti, M. P. (2015). Graphene oxide selectively targets cancer stem cells, across multiple tumor types: implications for non-toxic cancer treatment, via "differentiation-based nanotherapy". Oncotarget, 6(6), 3553-3562. https://doi.org/10.18632/oncotarget.3348 
93. Chen, Z., Mao, R., \& Liu, Y. (2012). Fullerenes for cancer diagnosis and therapy: preparation, biological and clinical perspectives. Current drug metabolism, 13(8), 1035-1045. https://doi.org/10.2174/138920012802850128

94. Mroz, P., Tegos, G. P., Gali, H., Wharton, T., Sarna, T., \& Hamblin, M. R. (2007). Photodynamic therapy with fullerenes. Photochemical \& photobiological sciences : Official journal of the European Photochemistry Association and the European Society for Photobiology, 6(11), 1139-1149. https://doi.org/10.1039/b711141j

95. Tabata, Y., Murakami, Y., \& Ikada, Y. (1997). Photodynamic effect of polyethylene glycol-modified fullerene on tumor. Japanese journal of cancer research : Gann, 88(11), 1108-1116. https://doi.org/10.1111/j.1349-7006.1997.tb00336.x

96. Heister, E., Neves, V., Tîlmaciu, C., Lipert, K., Beltrán, V.S., Coley, H., Silva, S.R., \& McFadden, J. (2009). Triple functionalisation of single-walled carbon nanotubes with doxorubicin, a monoclonal antibody, and a fluorescent marker for targeted cancer therapy. Carbon, 47, 2152-2160.

97. Jamieson, T., Bakhshi, R., Petrova, D., Pocock, R., Imani, M., \& Seifalian, A. M. (2007). Biological applications of quantum dots. Biomaterials, 28(31), 4717-4732. https://doi.org/10.1016/j.biomaterials.2007.07.014

98. Bagalkot, V., Zhang, L., Levy-Nissenbaum, E., Jon, S., Kantoff, P. W., Langer, R., \& Farokhzad, O. C. (2007). Quantum dot-aptamer conjugates for synchronous cancer imaging, therapy, and sensing of drug delivery based on bi-fluorescence resonance energy transfer. Nano letters, 7(10), 3065-3070. https://doi.org/10.1021/n1071546n

99. Xu, Z. P., Zeng, Q. H., Lu, G. Q., \& Yu, A. B. (2006). Inorganic nanoparticles as carriers for efficient cellular delivery. Chemical Engineering Science, 61(3), 10271040 .

100. Zhao, X., Hilliard, L. R., Mechery, S. J., Wang, Y., Bagwe, R. P., Jin, S., \& Tan, W. (2004). A rapid bioassay for single bacterial cell quantitation using bioconjugated nanoparticles. Proceedings of the National Academy of Sciences of the United States of America, 101(42), 15027-15032. https://doi.org/10.1073/pnas.0404806101

101. Mousa, S. A., \& Bharali, D. J. (2011). Nanotechnology-based detection and targeted therapy in cancer: nano-bio paradigms and applications. Cancers, 3(3), 28882903. https://doi.org/10.3390/cancers3032888

102. Schroeder, A., Heller, D. A., Winslow, M. M., Dahlman, J. E., Pratt, G. W., Langer, R., Jacks, T., \& Anderson, D. G. (2011). Treating metastatic cancer with nanotechnology. Nature reviews. Cancer, 12(1), 39-50. https://doi.org/10.1038/nrc3180

103. Castaneda, R. T., Khurana, A., Khan, R., \& Daldrup-Link, H. E. (2011). Labeling stem cells with ferumoxytol, an FDA-approved iron oxide nanoparticle. Journal of visualized experiments : JoVE, (57), e3482. https://doi.org/10.3791/3482

104. Basoglu, H., Goncu, B., \& Akbas, F. (2018). Magnetic nanoparticle-mediated gene therapy to induce Fas apoptosis pathway in breast cancer. Cancer gene therapy, 25(5-6), 141-147. https://doi.org/10.1038/s41417-018-0017-2

105. Meng, J., Fan, J., Galiana, G., Branca, R., Clasen, P., Ma, S., . . Soboyejo, W. (2009). LHRH-functionalized superparamagnetic iron oxide nanoparticles for breast cancer targeting and contrast enhancement in MRI. Materials Science and Engineering: C, 29(4), 1467-1479. doi:10.1016/j.msec.2008.09.039

106. Hoopes, P. J., Moodie, K. L., Petryk, A. A., Petryk, J. D., Sechrist, S., Gladstone, D. J., Steinmetz, N. F., Veliz, F. A., Bursey, A. A., Wagner, R. J., Rajan, A., Dugat, D., Crary-Burney, M., \& Fiering, S. N. (2017). Hypo-fractionated Radiation, 
Magnetic Nanoparticle Hyperthermia and a Viral Immunotherapy Treatment of Spontaneous Canine Cancer. Proceedings of SPIE--the International Society for Optical Engineering, 10066, 1006605. https://doi.org/10.1117/12.2256213

107. Legge, C. J., Colley, H. E., Lawson, M. A., \& Rawlings, A. E. (2019). Targeted magnetic nanoparticle hyperthermia for the treatment of oral cancer. Journal of oral pathology \& medicine : official publication of the International Association of Oral Pathologists and the American Academy of Oral Pathology, 48(9), 803-809. https://doi.org/10.1111/jop.12921

108. Maurya, A., Singh, A. K., Mishra, G., Kumari, K., Rai, A., Sharma, B., Kulkarni, G. T., \& Awasthi, R. (2019). Strategic use of nanotechnology in drug targeting and its consequences on human health: A focused review. Interventional medicine \& applied science, 11(1), 38-54. https://doi.org/10.1556/1646.11.2019.04

109. Khosravi-Darani, K., Mozafari, M. R., Rashidi, L., \& Mohammadi, M. (2010). Calcium based non-viral gene delivery: an overview of methodology and applications. Acta medica Iranica, 48(3), 133-141.

110. Mozafari, M. R., Reed, C. J., Rostron, C., Kocum, C., \& Piskin, E. (2002). Construction of stable anionic liposome-plasmid particles using the heating method: a preliminary investigation. Cellular \& molecular biology letters, 7(3), 923-927.

111. Mozafari, M. R., Reed, C. J., \& Rostron, C. (2007). Cytotoxicity evaluation of anionic nanoliposomes and nanolipoplexes prepared by the heating method without employing volatile solvents and detergents. Die Pharmazie, 62(3), 205-209.

112. Katragadda, C., Choudhury, P. and Murthy, P., 2021. Nanoparticles as NonViral Gene Delivery Vectors. [online] Ijper.org. Available at: $<$ http://www.ijper.org/article/259> [Accessed 30 July 2021].

113. Kneuer, C., Sameti, M., Bakowsky, U., Schiestel, T., Schirra, H., Schmidt, H., \& Lehr, C. M. (2000). A nonviral DNA delivery system based on surface modified silica-nanoparticles can efficiently transfect cells in vitro. Bioconjugate chemistry, 11(6), 926-932. https://doi.org/10.1021/bc0000637

114. Gary-Bobo, M., Hocine, O., Brevet, D., Maynadier, M., Raehm, L., Richeter, S., Charasson, V., Loock, B., Morère, A., Maillard, P., Garcia, M., \& Durand, J. O. (2012). Cancer therapy improvement with mesoporous silica nanoparticles combining targeting, drug delivery and PDT. International journal of pharmaceutics, 423(2), 509515. https://doi.org/10.1016/j.ijpharm.2011.11.045

115. Duchêne, D., Ponchel, G., \& Wouessidjewe, D. (1999). Cyclodextrins in targeting. Application to nanoparticles. Advanced drug delivery reviews, 36(1), 29-40. https://doi.org/10.1016/s0169-409x(98)00053-2

116. S, S., S, A., Krishnamoorthy, K., \& Rajappan, M. (2012). Nanosponges: a novel class of drug delivery system--review. Journal of pharmacy \& pharmaceutical sciences : a publication of the Canadian Society for Pharmaceutical Sciences, Societe canadienne des sciences pharmaceutiques, 15(1), 103-111. https://doi.org/10.18433/j3k308

117. Ansari, K. A., Torne, S. J., Vavia, P. R., Trotta, F., \& Cavalli, R. (2011). Paclitaxel loaded nanosponges: in-vitro characterization and cytotoxicity study on MCF-7 cell line culture. Current drug delivery, 8(2), 194-202. https://doi.org/10.2174/156720111794479934

118. Swaminathan, S., Pastero, L., Serpe, L., Trotta, F., Vavia, P., Aquilano, D., Trotta, M., Zara, G., \& Cavalli, R. (2010). Cyclodextrin-based nanosponges encapsulating camptothecin: physicochemical characterization, stability and cytotoxicity. European journal of pharmaceutics and biopharmaceutics : official 
journal of Arbeitsgemeinschaft fur Pharmazeutische Verfahrenstechnik e.V, 74(2), 193-201. https://doi.org/10.1016/j.ejpb.2009.11.003

119. Zang, X., Zhao, X., Hu, H., Qiao, M., Deng, Y., \& Chen, D. (2017). Nanoparticles for tumor immunotherapy. European journal of pharmaceutics and biopharmaceutics : official journal of Arbeitsgemeinschaft fur Pharmazeutische Verfahrenstechnik e.V, 115, 243-256. https://doi.org/10.1016/j.ejpb.2017.03.013

120. Yan, S., Luo, Z., Li, Z., Wang, Y., Tao, J., Gong, C., \& Liu, X. (2020). Improving Cancer Immunotherapy Outcomes Using Biomaterials. Angewandte Chemie (International ed. in English), 59(40), 17332-17343. https://doi.org/10.1002/anie.202002780

121. Paulis, L. E., Mandal, S., Kreutz, M., \& Figdor, C. G. (2013). Dendritic cellbased nanovaccines for cancer immunotherapy. Current opinion in immunology, 25(3), 389-395. https://doi.org/10.1016/j.coi.2013.03.001

122. Shao, K., Singha, S., Clemente-Casares, X., Tsai, S., Yang, Y., \& Santamaria, P. (2015). Nanoparticle-based immunotherapy for cancer. ACS nano, 9(1), 16-30. https://doi.org/10.1021/nn5062029

123. Yang, R., Xu, J., Xu, L., Sun, X., Chen, Q., Zhao, Y., Peng, R., \& Liu, Z. (2018). Cancer Cell Membrane-Coated Adjuvant Nanoparticles with Mannose Modification for Effective Anticancer Vaccination. ACS nano, 12(6), 5121-5129. https://doi.org/10.1021/acsnano.7b09041

124. Guo, Y., Wang, D., Song, Q., Wu, T., Zhuang, X., Bao, Y., Kong, M., Qi, Y., Tan, S., \& Zhang, Z. (2015). Erythrocyte Membrane-Enveloped Polymeric Nanoparticles as Nanovaccine for Induction of Antitumor Immunity against Melanoma. ACS nano, 9(7), 6918-6933. https://doi.org/10.1021/acsnano.5b01042

125. Fontana, F., Shahbazi, M-A., Liu, D., Zhang, H., Mäkilä, E., Salonen, J., Hirvonen, J. T., \& Almeida Santos, H. (2017). Multistaged Nanovaccines based on Porous Silicon@Acetalated Dextran@Cancer Cell Membrane for Cancer Immunotherapy. Advanced [1603239]. https://doi.org/10.1002/adma.201603239

Materials, 29(7),

126. Perica, K., De León Medero, A., Durai, M., Chiu, Y. L., Bieler, J. G., Sibener, L., Niemöller, M., Assenmacher, M., Richter, A., Edidin, M., Oelke, M., \& Schneck, J. (2014). Nanoscale artificial antigen presenting cells for $T$ cell immunotherapy. Nanomedicine : nanotechnology, biology, and medicine, 10(1), 119129. https://doi.org/10.1016/j.nano.2013.06.015

127. Bauleth-Ramos, T., Shahbazi, M., Liu, D., Fontana, F., Correia, A., Figueiredo, P., ... Santos, H. A. (2017). Nutlin-3a and Cytokine Co-loaded Spermine-Modified Acetalated Dextran Nanoparticles for Cancer Chemo-Immunotherapy. Advanced Functional Materials, 27(42), 1703303. doi:10.1002/adfm.201703303

128. Liu, Y. T., \& Sun, Z. J. (2021). Turning cold tumors into hot tumors by improving T-cell infiltration. Theranostics, 11(11), 5365-5386. https://doi.org/10.7150/thno.58390

129. Bu, J., Nair, A., Iida, M., Jeong, W. J., Poellmann, M. J., Mudd, K., Kubiatowicz, L. J., Liu, E. W., Wheeler, D. L., \& Hong, S. (2020). An Avidity-Based PD-L1 Antagonist Using Nanoparticle-Antibody Conjugates for Enhanced Immunotherapy. Nano letters, 20(7), 4901-4909. https://doi.org/10.1021/acs.nanolett.0c00953

130. Hou, Y., Sun, Z., Rao, W., \& Liu, J. (2018). Nanoparticle-mediated cryosurgery for tumor therapy. Nanomedicine : nanotechnology, biology, and medicine, 14(2), 493506. https://doi.org/10.1016/j.nano.2017.11.018 
131. Liu, J., \& Deng, Z. S. (2009). Nano-cryosurgery: advances and challenges. Journal of nanoscience and nanotechnology,9(8), 4521-4542. https://doi.org/10.1166/jnn.2009.1264

132. Di, D. R., He, Z. Z., Sun, Z. Q., \& Liu, J. (2012). A new nano-cryosurgical modality for tumor treatment using biodegradable $\mathrm{MgO}$ nanoparticles. Nanomedicine: nanotechnology, biology, and medicine, 8(8), 1233-1241. https://doi.org/10.1016/j.nano.2012.02.010

133. Chua, K. J., Chou, S. K., \& Ho, J. C. (2007). An analytical study on the thermal effects of cryosurgery on selective cell destruction. Journal of biomechanics, 40(1), 100-116. https://doi.org/10.1016/j.jbiomech.2005.11.005

134. Yonggang, L., Yang, Z., \& Yang, L. (2021). Uncertainty and sensitivity analysis of properties of phase change micro/nanoparticles for thermal protection during cryosurgery | Lv, Yonggang; Zou, Yang; Yang, Li | download. Booksc.eu. Retrieved 30 July 2021, from https://booksc.eu/book/12821610/234c88.

135. Housman, G., Byler, S., Heerboth, S., Lapinska, K., Longacre, M., Snyder, N., \& Sarkar, S. (2014). Drug resistance in cancer: an overview. Cancers, 6(3), 1769-1792. https://doi.org/10.3390/cancers6031769

136. Schneider, E., \& Hunke, S. (1998). ATP-binding-cassette (ABC) transport systems: functional and structural aspects of the ATP-hydrolyzing subunits/domains. FEMS microbiology reviews, 22(1), 1-20. https://doi.org/10.1111/j.1574-6976.1998.tb00358.x

137. Allen, J. D., Brinkhuis, R. F., van Deemter, L., Wijnholds, J., \& Schinkel, A. H. (2000). Extensive contribution of the multidrug transporters P-glycoprotein and Mrp1 to basal drug resistance. Cancer research, 60(20), 5761-5766.

138. Chintamani, Singh, J. P., Mittal, M. K., Saxena, S., Bansal, A., Bhatia, A., \& Kulshreshtha, P. (2005). Role of p-glycoprotein expression in predicting response to neoadjuvant chemotherapy in breast cancer--a prospective clinical study. World journal of surgical oncology, 3, 61. https://doi.org/10.1186/1477-7819-3-61

139. Agarwal, R., \& Kaye, S. B. (2003). Ovarian cancer: strategies for overcoming resistance to chemotherapy. Nature reviews. Cancer, 3(7), 502-516. https://doi.org/10.1038/nrc1123

140. Murakami, M., Cabral, H., Matsumoto, Y., Wu, S., Kano, M. R., Yamori, T., Nishiyama, N., \& Kataoka, K. (2011). Improving drug potency and efficacy by nanocarrier-mediated subcellular targeting. Science translational medicine, 3(64), 64ra2. https://doi.org/10.1126/scitranslmed.3001385

141. Yu, B., Song, N., Hu, H., Chen, G., Shen, Y., \& Cong, H. (2018). A degradable triple temperature-, $\mathrm{pH}-$, and redox-responsive drug system for cancer chemotherapy. Journal of biomedical materials research. Part A, 106(12), 3203-3210. https://doi.org/10.1002/jbm.a.36515

142. Kundu, M., Sadhukhan, P., Ghosh, N., Chatterjee, S., Manna, P., Das, J., \& Sil, P. C. (2019). pH-responsive and targeted delivery of curcumin via phenylboronic acidfunctionalized $\mathrm{ZnO}$ nanoparticles for breast cancer therapy. Journal of advanced research, 18, 161-172. https://doi.org/10.1016/j.jare.2019.02.036

143. Cuvier, C., Roblot-Treupel, L., Millot, J. M., Lizard, G., Chevillard, S., Manfait, M., Couvreur, P., \& Poupon, M. F. (1992). Doxorubicin-loaded nanospheres bypass tumor cell multidrug resistance. Biochemical pharmacology, 44(3), 509-517. https://doi.org/10.1016/0006-2952(92)90443-m

144. Soma, C. E., Dubernet, C., Bentolila, D., Benita, S., \& Couvreur, P. (2000). Reversion of multidrug resistance by co-encapsulation of doxorubicin and cyclosporin 
A in polyalkylcyanoacrylate nanoparticles. Biomaterials, 21(1), 1-7. https://doi.org/10.1016/s0142-9612(99)00125-8

145. Zhang, S., Guo, N., Wan, G., Zhang, T., Li, C., Wang, Y., Wang, Y., \& Liu, Y. (2019). $\mathrm{pH}$ and redox dual-responsive nanoparticles based on disulfide-containing poly $(\beta$-amino ester) for combining chemotherapy and COX-2 inhibitor to overcome drug resistance in breast cancer. Journal of nanobiotechnology, 17(1), 109. https://doi.org/10.1186/s12951-019-0540-9

146. He, J., Gong, C., Qin, J., Li, M., \& Huang, S. (2019). Cancer Cell Membrane Decorated Silica Nanoparticle Loaded with miR495 and Doxorubicin to Overcome Drug Resistance for Effective Lung Cancer Therapy. Nanoscale research letters, 14(1), 339. https://doi.org/10.1186/s11671-019-3143-3

147. Viktorsson, K., Lewensohn, R., \& Zhivotovsky, B. (2005). Apoptotic pathways and therapy resistance in human malignancies. Advances in cancer research, 94, 143196. https://doi.org/10.1016/S0065-230X(05)94004-9

148. Choi, K. Y., Correa, S., Min, J., Li, J., Roy, S., Laccetti, K. H., Dreaden, E., Kong, S., Heo, R., Roh, Y. H., Lawson, E. C., Palmer, P. A., \& Hammond, P. T. (2019). Binary Targeting of siRNA to Hematologic Cancer Cells In Vivo using Layer-by-Layer Nanoparticles. Advanced functional materials, 29(20), 1900018. https://doi.org/10.1002/adfm.201900018

149. Fan, L., Li, F., Zhang, H., Wang, Y., Cheng, C., Li, X., Gu, C. H., Yang, Q., Wu, H., \& Zhang, S. (2010). Co-delivery of PDTC and doxorubicin by multifunctional micellar nanoparticles to achieve active targeted drug delivery and overcome multidrug resistance. Biomaterials, 31(21), $5634-5642$. https://doi.org/10.1016/j.biomaterials.2010.03.066

150. Zhao, M. D., Li, J. Q., Chen, F. Y., Dong, W., Wen, L. J., Fei, W. D., Zhang, X., Yang, P. L., Zhang, X. M., \& Zheng, C. H. (2019). Co-Delivery of Curcumin and Paclitaxel by "Core-Shell" Targeting Amphiphilic Copolymer to Reverse Resistance in the Treatment of Ovarian Cancer. International journal of nanomedicine, 14, 94539467. https://doi.org/10.2147/IJN.S224579

151. van Vlerken, L. E., Duan, Z., Little, S. R., Seiden, M. V., \& Amiji, M. M. (2010). Augmentation of therapeutic efficacy in drug-resistant tumor models using ceramide coadministration in temporal-controlled polymer-blend nanoparticle delivery systems. The AAPS journal, 12(2), 171-180. https://doi.org/10.1208/s12248-0109174-4

152. Khiste, S. K., Liu, Z., Roy, K. R., Uddin, M. B., Hosain, S. B., Gu, X., Nazzal, S., Hill, R. A., \& Liu, Y. Y. (2020). Ceramide-Rubusoside Nanomicelles, a Potential Therapeutic Approach to Target Cancers Carrying p53 Missense Mutations. Molecular cancer therapeutics, 19(2), 564-574. https://doi.org/10.1158/1535-7163.MCT-190366

153. Choi, S. H., Jin, S. E., Lee, M. K., Lim, S. J., Park, J. S., Kim, B. G., Ahn, W. S., \& Kim, C. K. (2008). Novel cationic solid lipid nanoparticles enhanced p53 gene transfer to lung cancer cells. European journal of pharmaceutics and biopharmaceutics : official journal of Arbeitsgemeinschaft fur Pharmazeutische Verfahrenstechnik e.V, 68(3), 545-554. https://doi.org/10.1016/j.ejpb.2007.07.011

154. Prabha, S., \& Labhasetwar, V. (2004). Nanoparticle-mediated wild-type p53 gene delivery results in sustained antiproliferative activity in breast cancer cells. Molecular pharmaceutics, 1(3), 211-219. https://doi.org/10.1021/mp049970+

155. Cheng $\mathrm{H}, \mathrm{Wu} \mathrm{Z}, \mathrm{Wu} \mathrm{C}$, et al. Overcoming STC2 mediated drug resistance through drug and gene co-delivery by PHB-PDMAEMA cationic polyester in liver 
cancer cells. Materials Science \& engineering. C, Materials for Biological Applications. 2018 Feb;83:210-217. DOI: 10.1016/j.msec.2017.08.075.

156. Zhao, Y., Huan, M. L., Liu, M., Cheng, Y., Sun, Y., Cui, H., Liu, D. Z., Mei, Q. B., \& Zhou, S. Y. (2016). Doxorubicin and resveratrol co-delivery nanoparticle to overcome doxorubicin resistance. Scientific reports, 6, 35267. https://doi.org/10.1038/srep35267

157. Singh, S. K., Lillard, J. W., Jr, \& Singh, R. (2018). Reversal of drug resistance by planetary ball milled (PBM) nanoparticle loaded with resveratrol and docetaxel in prostate cancer. Cancer letters, 427, 49-62. https://doi.org/10.1016/j.canlet.2018.04.017

158. Jing, X., Yang, F., Shao, C., Wei, K., Xie, M., Shen, H., \& Shu, Y. (2019). Role of hypoxia in cancer therapy by regulating the tumor microenvironment. Molecular cancer, 18(1), 157. https://doi.org/10.1186/s12943-019-1089-9

159. Luo B, Li W, Wang R, et al. [Effect of hypoxia on expression of multidrug resistance protein 2 and its regulation mechanism]. Zhong nan da xue xue bao. Yi xue ban $=$ Journal of Central South University. Medical Sciences. 2017 Jan;42(1):98-107. DOI: $10.11817 / \mathrm{j}$.issn

160. Hajizadeh, F., Moghadaszadeh Ardebili, S., Baghi Moornani, M., Masjedi, A., Atyabi, F., Kiani, M., Namdar, A., Karpisheh, V., Izadi, S., Baradaran, B., Azizi, G., Ghalamfarsa, G., Sabz, G., Yousefi, M., \& Jadidi-Niaragh, F. (2020). Silencing of HIF$1 \alpha /$ CD73 axis by siRNA-loaded TAT-chitosan-spion nanoparticles robustly blocks cancer cell progression. European journal of pharmacology, 882, 173235. https://doi.org/10.1016/j.ejphar.2020.173235

161. Zhang, J., Zhang, Q., Lou, Y., Fu, Q., Chen, Q., Wei, T., Yang, J., Tang, J., Wang, J., Chen, Y., Zhang, X., Zhang, J., Bai, X., \& Liang, T. (2018). Hypoxiainducible factor-1 $\alpha /$ interleukin-1 $\beta$ signaling enhances hepatoma epithelialmesenchymal transition through macrophages in a hypoxic-inflammatory microenvironment. Hepatology (Baltimore, Md.), 67(5), 1872-1889. https://doi.org/10.1002/hep.29681

162. Semenza G. L. (2007). Evaluation of HIF-1 inhibitors as anticancer agents. Drug discovery today, 12(19-20), 853-859. https://doi.org/10.1016/j.drudis.2007.08.006

163. Long, Q., Lin, T. Y., Huang, Y., Li, X., Ma, A. H., Zhang, H., Carney, R., Airhart, S., Lam, K. S., deVere White, R. W., Pan, C. X., \& Li, Y. (2018). Image-guided photo-therapeutic nanoporphyrin synergized HSP90 inhibitor in patient-derived xenograft bladder cancer model. Nanomedicine : nanotechnology, biology, and medicine, 14(3), 789-799. https://doi.org/10.1016/j.nano.2017.12.014

164. Sebak, A. A., Gomaa, I., ElMeshad, A. N., Farag, M. H., Breitinger, U., Breitinger, H. G., \& AbdelKader, M. H. (2020). Distinct Proteins in Protein Corona of Nanoparticles Represent a Promising Venue for Endogenous Targeting - Part I: In vitro Release and Intracellular Uptake Perspective. International journal of nanomedicine, 15, 8845-8862. https://doi.org/10.2147/IJN.S273713

165. Vroman, L., Adams, A. L., Fischer, G. C., \& Munoz, P. C. (1980). Interaction of high molecular weight kininogen, factor XII, and fibrinogen in plasma at interfaces. Blood, 55(1), 156-159.

166. Pederzoli, F., Tosi, G., Vandelli, M. A., Belletti, D., Forni, F., \& Ruozi, B. (2017, March 15). Protein corona and nanoparticles: How can we investigate on? Retrieved July 30, 2021, from https://wires.onlinelibrary.wiley.com/doi/abs/10.1002/wnan.1467 
167. Risha, Y., Minic, Z., Ghobadloo, S. M., \& Berezovski, M. V. (2020). The proteomic analysis of breast cell line exosomes reveals disease patterns and potential biomarkers. Scientific reports, 10(1), 13572. https://doi.org/10.1038/s41598-02070393-4

168. Burnett, J. C., Rossi, J. J., \& Tiemann, K. (2011). Current progress of siRNA/shRNA therapeutics in clinical trials. Biotechnology journal, 6(9), 1130-1146. https://doi.org/10.1002/biot.201100054

169. Aleku, M., Schulz, P., Keil, O., Santel, A., Schaeper, U., Dieckhoff, B., Janke, O., Endruschat, J., Durieux, B., Röder, N., Löffler, K., Lange, C., Fechtner, M., Möpert, K., Fisch, G., Dames, S., Arnold, W., Jochims, K., Giese, K., Wiedenmann, B., ... Kaufmann, J. (2008). Atu027, a liposomal small interfering RNA formulation targeting protein kinase N3, inhibits cancer progression. Cancer research, 68(23), 9788-9798. https://doi.org/10.1158/0008-5472.CAN-08-2428

170. Winter, J., Jung, S., Keller, S., Gregory, R. I., \& Diederichs, S. (2009). Many roads to maturity: microRNA biogenesis pathways and their regulation. Nature cell biology, 11(3), 228-234. https://doi.org/10.1038/ncb0309-228

171. Kato, R. B., Roy, B., De Oliveira, F. S., Ferraz, E. P., De Oliveira, P. T., Kemper, A. G., Hassan, M. Q., Rosa, A. L., \& Beloti, M. M. (2014). Nanotopography directs mesenchymal stem cells to osteoblast lineage through regulation of microRNASMAD-BMP-2 circuit. Journal of cellular physiology,229(11), 1690-1696. https://doi.org/10.1002/jcp.24614

172. Bobo, D., Robinson, K. J., Islam, J., Thurecht, K. J., \& Corrie, S. R. (2016). Nanoparticle-based medicines: a review of FDA-approved materials and clinical trials to date. Pharmaceutical research, 33(10), 2373-2387

173. Ventola C. L. (2017). Progress in Nanomedicine: Approved and Investigational Nanodrugs. $P \& T:$ a peer-reviewed journal for formulary management, 42(12), 742755.

174. Lombardo, D., Kiselev, M. A., \& Caccamo, M. T. (2019). Smart nanoparticles for drug delivery application: development of versatile nanocarrier platforms in biotechnology and nanomedicine. Journal of Nanomaterials, 2019

175. Rezvantalab, S., Drude, N. I., Moraveji, M. K., Güvener, N., Koons, E. K., Shi, Y., ... \& Kiessling, F. (2018). PLGA-based nanoparticles in cancer treatment. Frontiers in pharmacology, 9, 1260

176. Yona, S., \& Gordon, S. (2015). From the Reticuloendothelial to Mononuclear Phagocyte System - The Unaccounted Years. Frontiers in immunology, 6, 328. https://doi.org/10.3389/fimmu.2015.00328

177. Liang, T., Zhang, R., Liu, X., Ding, Q., Wu, S., Li, C., Lin, Y., Ye, Y., Zhong, Z., \& Zhou, M. (2021). Recent Advances in Macrophage-Mediated Drug Delivery Systems. International journal of nanomedicine, 16, 2703-2714. https://doi.org/10.2147/IJN.S298159

178. Tran, S., DeGiovanni, P. J., Piel, B., \& Rai, P. (2017). Cancer nanomedicine: a review of recent success in drug delivery. Clinical and translational medicine, 6(1), 44. https://doi.org/10.1186/s40169-017-0175-0

179. Hu, Y., Gaillard, P. J., de Lange, E., \& Hammarlund-Udenaes, M. (2019). Targeted brain delivery of methotrexate by glutathione PEGylated liposomes: How can the formulation make a difference?. European journal of pharmaceutics and biopharmaceutics : official journal of Arbeitsgemeinschaft fur Pharmazeutische Verfahrenstechnik e.V, 139, 197-204. https://doi.org/10.1016/j.ejpb.2019.04.004

180. Feng, Q., Shen, Y., Fu, Y., Muroski, M. E., Zhang, P., Wang, Q., Xu, C., Lesniak, M. S., Li, G., \& Cheng, Y. (2017). Self-Assembly of Gold Nanoparticles 
Shows Microenvironment-Mediated Dynamic Switching and Enhanced Brain Tumor Targeting. Theranostics, 7(7), 1875-1889. https://doi.org/10.7150/thno.18985

181. Wu, L., Zhang, J., \& Watanabe, W. (2011). Physical and chemical stability of drug nanoparticles. Advanced drug delivery reviews, 63(6), 456-469. https://doi.org/10.1016/j.addr.2011.02.001

182. Brigger, I., Dubernet, C., \& Couvreur, P. (2002). Nanoparticles in cancer therapy and diagnosis. Advanced drug delivery reviews, 54(5), 631-651. https://doi.org/10.1016/s0169-409x(02)00044-3

183. Desai, M. P., Labhasetwar, V., Amidon, G. L., \& Levy, R. J. (1996). Gastrointestinal uptake of biodegradable microparticles: effect of particle size. Pharmaceutical research, 13(12), 1838-1845. https://doi.org/10.1023/a:1016085108889

184. Ryman-Rasmussen, Jessica P., et al. "Penetration of Intact Skin by Quantum Dots with Diverse Physicochemical Properties." Toxicological Sciences, vol. 91, no. 1, 27 Jan. 2006, pp. 159-165, 10.1093/toxsci/kfj122. Accessed 6 June 2021.

185. Jia, G., Han, Y., An, Y., Ding, Y., He, C., Wang, X., \& Tang, Q. (2018). NRP1 targeted and cargo-loaded exosomes facilitate simultaneous imaging and therapy of glioma in vitro and in vivo. Biomaterials, 178, 302-316. https://doi.org/10.1016/j.biomaterials.2018.06.029

186. Jiang, J., Oberdörster, G. \& Biswas, P. Characterization of size, surface charge, and agglomeration state of nanoparticle dispersions for toxicological studies. $J$ Nanopart Res 11, 77-89 (2009). https://doi.org/10.1007/s11051-008-9446-4

187. Awasthi, R., Pant, I., T Kulkarni, G., Satiko Kikuchi, I., de Jesus Andreoli Pinto, T., Dua, K., \& Ramana Malipeddi, V. (2016). Opportunities and challenges in nanostructure mediated drug delivery: Where do we stand?. Current Nanomedicine (Formerly: Recent Patents on Nanomedicine), 6(2), 78-104

188. Xia, T., Kovochich, M., Brant, J., Hotze, M., Sempf, J., Oberley, T., Sioutas, C., Yeh, J. I., Wiesner, M. R., \& Nel, A. E. (2006). Comparison of the abilities of ambient and manufactured nanoparticles to induce cellular toxicity according to an oxidative stress paradigm. Nano letters, 6(8), 1794-1807. https://doi.org/10.1021/n1061025k

189. Xia, Y., Rao, L., Yao, H., Wang, Z., Ning, P., \& Chen, X. (2020, August 28). Engineering Macrophages for Cancer Immunotherapy and Drug Delivery. Retrieved from https://onlinelibrary.wiley.com/doi/abs/10.1002/adma.202002054

190. Dobrovolskaia, M. A., Aggarwal, P., Hall, J. B., \& McNeil, S. E. (2008). Preclinical studies to understand nanoparticle interaction with the immune system and its potential effects on nanoparticle biodistribution. Molecular pharmaceutics, 5(4), 487-495. https://doi.org/10.1021/mp800032f

191. Akinc, A., Zumbuehl, A., Goldberg, M., Leshchiner, E. S., Busini, V., Hossain, N., Bacallado, S. A., Nguyen, D. N., Fuller, J., Alvarez, R., Borodovsky, A., Borland, T., Constien, R., de Fougerolles, A., Dorkin, J. R., Narayanannair Jayaprakash, K., Jayaraman, M., John, M., Koteliansky, V., Manoharan, M., ... Anderson, D. G. (2008). A combinatorial library of lipid-like materials for delivery of RNAi therapeutics. Nature biotechnology, 26(5), 561-569. https://doi.org/10.1038/nbt1402

192. Love, K. T., Mahon, K. P., Levins, C. G., Whitehead, K. A., Querbes, W., Dorkin, J. R., Qin, J., Cantley, W., Qin, L. L., Racie, T., Frank-Kamenetsky, M., Yip, K. N., Alvarez, R., Sah, D. W., de Fougerolles, A., Fitzgerald, K., Koteliansky, V., Akinc, A., Langer, R., \& Anderson, D. G. (2010). Lipid-like materials for low-dose, in vivo gene silencing. Proceedings of the National Academy of Sciences of the United States of America, 107(5), 1864-1869. https://doi.org/10.1073/pnas.0910603106 
193. Schork N. J. (2015). Personalized medicine: Time for one-person trials. Nature, 520(7549), 609-611. https://doi.org/10.1038/520609a 